\title{
1 Bookshelf Kinematics and the Effect of Dilatation on Fault \\ 2 Zone Inelastic Deformation: Examples from Optical Image \\ Earthquake Sequence
}

5
Christopher Milliner ${ }^{1,2^{*}}$, Andrea Donnellan ${ }^{1}$, Saif Aati ${ }^{2}$, Jean-Philippe Avouac ${ }^{2}$, Robert Zinke ${ }^{1}$, James F. Dolan ${ }^{3}$, Kang Wang ${ }^{4}$, Roland Bürgmann ${ }^{4}$

${ }^{1}$ Jet Propulsion Laboratory, California Institute of Technology, Pasadena, CA

${ }^{2}$ California Institute of Technology, Pasadena, CA

${ }^{3}$ University of Southern California, Los Angeles, CA

${ }^{4}$ University of California, Berkeley, Berkeley, CA

*corresponding author.milliner@caltech.edu

This manuscript has been submitted for publication in Journal of Geophysical Research:Solid Earth. Please note that the peer-review is in progress, and subsequent versions of this manuscript may have different content. If accepted, the final version of this manuscript will be available via the 'Peer-reviewed publication DOI' link on the EarthArxiv webpage. 


\section{Bookshelf Kinematics and the Effect of Dilatation on Fault Zone Inelastic} Deformation: Examples from Optical Image Correlation Measurements of the 2019 Ridgecrest Earthquake Sequence

Christopher Milliner ${ }^{1,2^{*}}$, Andrea Donnellan ${ }^{1}$, Saif Aati ${ }^{2}$, Jean-Philippe Avouac ${ }^{2}$, Robert Zinke ${ }^{1}$,

36 James F. Dolan ${ }^{3}$, Kang Wang ${ }^{4}$, Roland Bürgmann ${ }^{4}$

${ }^{1}$ Jet Propulsion Laboratory, California Institute of Technology, Pasadena, CA

$39 \quad{ }^{2}$ California Institute of Technology, Pasadena, CA

$40 \quad{ }^{3}$ University of Southern California, Los Angeles, CA

$41{ }^{4}$ University of California, Berkeley, Berkeley, CA

42 *corresponding author

Key Points

- We resolve finite strain, rotation and dilatation, finding wider fault zones with increasing extension such as transtensional bends

- Larger off-fault strain and a larger shallow slip-deficit suggests the foreshock occurred on a less mature fault system than the mainshock

- Large rotations beyond fault tips explain why conjugate faults do not intersect and that cross-faulting results from bookshelf kinematics 
64 The 2019 Ridgecrest earthquake sequence initiated on July $4^{\text {th }}$ with a series of foreshocks, 65 including a $\mathrm{M}_{\mathrm{w}} 6.4$ event, that culminated a day later with the $\mathrm{M}_{\mathrm{w}} 7.1$ mainshock and resulted in 66 rupture of a set of cross-faults. Here we use sub-pixel correlation of optical satellite imagery to 67 measure the displacement, finite strain and rotation of the near-field coseismic deformation to 68 understand the kinematics of strain release along the surface ruptures. We find the average off69 fault deformation along the mainshock rupture is $34 \%$ and is significantly higher along the 70 foreshock rupture (56\%) suggesting it is a less structurally developed fault system. Measurements 71 of the 2D dilatational strain along the mainshock rupture show a dependency of the width of 72 inelastic strain with the degree of fault extension and contraction, indicating wider fault zones 73 under extension than under shear. Measurements of the vorticity along the main, dextral rupture 74 show that conjugate sinistral faults are embedded within zones of large clockwise rotations caused 75 by the transition of strain beyond the tips of dextral faults leading to bookshelf kinematics. These 76 rotations and bookshelf slip can explain why faults of different shear senses do not intersect one 77 another and the occurrence of pervasive and mechanically unfavorable cross-faulting in this 78 region. Understanding the causes for the variation of fault zone widths along surface ruptures has 79 importance for reducing the epistemic uncertainty of probabilistic models of distributed rupture 80 that will in turn provide more precise estimates of the hazard distributed rupture poses to nearby 81 infrastructure.

84 Keywords: Ridgecrest, inelastic, off-fault deformation, finite strain, rotation, dilatation, 85 distributed rupture

\subsection{Introduction}

91 The 2019 Ridgecrest earthquake sequence initiated on July $4^{\text {th }}$ with a series of foreshocks that 92 included a $\mathrm{M}_{\mathrm{w}} 6.4$ event and culminated 34 hours later with a $\mathrm{M}_{\mathrm{w}} 7.1$ mainshock event. This 
93 sequence was also notable in that it resulted in rupture of a set of more than 20 cross-faults

94 (Brandenberg et al., 2020; Ross et al., 2019; Xu et al., 2020). The earthquake sequence occurred

95 within the northern region of the Eastern California Shear Zone (ECSZ), a 150-km-wide zone of

96 NW-trending dextral shear that accommodates up to $\sim 20 \%$ of the North America-Pacific plate

97 boundary motion (McClusky et al., 2001; Rockwell et al., 2000). Seismic and geodetic inversions

98 show the $\mathrm{M}_{\mathrm{w}} 6.4$ event likely ruptured multiple fault segments, where it initiated on a short NW-

99 trending, dextral fault, and then propagated to the southwest along a series of parallel NE-trending

100 sinistral faults for 16 km (Liu et al., 2019; Ross et al., 2019; Chen et al., 2020; Goldberg et al.,

1012020 ; Wang et al., 2020). On July $5^{\text {th }}, 34$ hours after the foreshock, the $\mathrm{M}_{\mathrm{w}} 7.1$ mainshock initiated

$102 \sim 15 \mathrm{~km}$ to the north, from where it propagated bilaterally at a relatively slow velocity of $\sim 2 \mathrm{~km} / \mathrm{s}$

103 along a NW-trending set of dextral faults for $\sim 45 \mathrm{~km}$. The mainshock rupture terminated at its

104 northern extent within the Coso volcanic field and at its southern extent $\sim 5 \mathrm{~km}$ from the Garlock

105 fault, where it was found to have triggered creep at the surface along parts of the Garlock fault and

106 a small cluster of seismicity (Barnhart et al., 2019; Ross et al., 2019). Field and remote-based

107 mapping of geomorphic markers and vegetation lineaments indicate that both fault systems

108 involved in the foreshock and mainshock show extensive evidence for faulting prior to their

109 rupture in 2019 (Jobe et al., 2020), but their geologic fault slip rates currently remain unknown.

110 The Ridgecrest sequence is also notable in that it occurred within a region of similar sized events,

111 including the $\mathrm{M}_{\mathrm{w}} \sim 7.51872$ Owens Valley earthquake located $\sim 45 \mathrm{~km}$ to the north, and the 1992

$112 \mathrm{M}_{\mathrm{w}} 7.3$ Landers and $1999 \mathrm{M}_{\mathrm{w}} 7.1$ Hector Mine earthquakes $\sim 110 \mathrm{~km}$ to the south.

113

114 Here we use optical image correlation of satellite data to measure the near-field surface

115 deformation patterns and study the kinematics of finite fault strain release along the Ridgecrest

116 surface ruptures. Documenting coseismic surface strain is important as we describe in section 1.2,

117 as it can alter the fault zone mechanical properties which are relevant to understanding earthquake

118 dynamics and is an important input for constraining probabilistic models of distributed fault

119 rupture hazard (e.g., Petersen et al., 2011). Here, we assess whether fault zones are wider and the

120 strain distribution is different under tension and assess the effects of rotations adjacent to faults

121 that may explain the occurrence of mechanically unfavorable cross-faulting. We also use our

122 observations of surface strain to shed light on the regional scale tectonic questions of the Eastern

123 California Shear Zone (ECSZ) and Garlock fault which we describe in the second section below. 


\subsection{Significance of distributed inelastic strain}

127 Distributed inelastic strain is accommodated via a range of mechanisms across fault zones, 128 including secondary fracturing, pervasive continuous shear and rotations (Shelef and Oskin, 2010).

129 These act to alter the mechanical properties of the fault zone material which in turn can affect a 130 range of earthquake processes including the attenuation of seismic waves (Mitchell, 1995), 131 dissipation of rupture energy and velocity (Sammis et al., 2010; Dunham et al., 2011; Gabriel et 132 al., 2013; Thomas and Bhat, 2018; Bao et al., 2019), and the ability of ruptures to fully reach the 133 surface (Kaneko and Fialko, 2011; Brooks et al., 2017). Therefore, understanding what controls

134 the variation of the magnitude, width and spatial decay of inelastic strain across fault zones has 135 importance for seismic hazard, both for accurately estimating the probability of seismic shaking 136 and distributed fault displacement (McGuire, 1995; Petersen et al., 2011). It is also important for 137 accurately estimating geologic fault slip rates that are susceptible to underestimating the long-term 138 displacement when restoring offset geomorphic features across fault zones (Dolan and Haravitch, 139 2014; Scharer et al., 2014).

141 Measurements of off-fault deformation (OFD) from field survey mapping and remote-based 142 methods (e.g. lidar differencing and optical image correlation) of surface ruptures have shown that 143 the sediment thickness, type of near-surface material and fault dip have an important effect on the 144 amounts of off-fault distributed inelastic deformation (Rockwell et al., 2002; Dolan and Haravitch, 145 2014; Zinke et al., 2014; Gold et al., 2015; Teran et al., 2015; Milliner et al., 2015; 2016; Scott et 146 al., 2018; Zhou et al., 2018). However, how the distribution and magnitude of inelastic strain varies 147 in regions where the fault experiences fault-normal contraction and extension is less well 148 understood. This is largely due to the difficulty of measuring the fault-perpendicular component 149 of displacement in the field and the challenge of accurately estimating strain from geodetic 150 displacement measurements which requires sufficiently high-resolution sampling and low noise 151 when calculating the spatial derivatives. Here we analyze the surface deformation due to the 2019 152 Ridgecrest earthquakes for which such types of data exist. Specifically, we use these pixel tracking 153 of pre- and post-earthquake optical satellite imagery to evaluate the sensitivity of the width and 
154 spatial attenuation of inelastic strain across the surface rupture to the amount of extension and 155 contraction the fault zone experiences.

157 From our observations of the kinematics of surface strain we also seek to understand the 158 widespread occurrence of orthogonal cross-faulting along the surface rupture. Cross-faulting occurred at almost all scales as shown by 100-m-long distributed fractures (Ponti et al., 2019; Xu

160 et al., 2020), to the coseismic rupture strands involved directly in the foreshock-mainshock 161 sequence and the distribution of aftershocks, which suggests cross-faulting is pervasive through 162 the seismogenic crust and is not just a surficial feature (Ross et al., 2019). Similar cross-faulting 163 rupture behavior has been observed during other large earthquakes (e.g., the 1987 Superstition

164 Hills) and seems to be a common mode of strain release along the North American-Pacific plate boundary (Hudnut et al., 1989; Smith et al., 2020). Although the occurrence of faults with nearly

166 orthogonal orientations is not uncommon, it is still poorly understood as the conventional Mohr167 Coulomb faulting theory predicts that faults form at $30^{\circ}$ from the direction of maximum 168 compression and $\sim 60^{\circ}$ from one another (Anderson, 1951). Here we attempt to understand why faults may occur in these mechanically unfavorable orientations relative to the background stress field by assessing the near-field kinematics along the Ridgecrest surface rupture at various scales which relate to different evolutionary stages of fault development.

173 We note that in our study we refer to the inelastic strain that is distributed across the fault zone and 174 adjacent to the primary fault strand as off-fault deformation (OFD) and not as fault damage. 175 Damage has been detected following major surface rupturing events by a decrease in the seismic 176 velocity across the fault zone that is thought to occur by the generation of microcracks which 177 reduces the rock's shear rigidity (Vidale and Li, 2003). Postseismically the seismic velocity of the 178 damaged material has been found to recover and increase with time due to the closing and healing 179 of microcracks, which indicates damage exhibits a time dependent behavior (Li et al., 2001). 180 Damage can also be generated by the dynamic passing seismic waves with very little true shear 181 strain in the form of shattered or "pulverized rocks" (Dor et al., 2006). In contrast the inelastic 182 strain that we measure here is permanent, occurs at a much larger spatial and displacement scale 183 (both $>10 \mathrm{~cm}$ 's) than microcracking and results from both the quasi-static and dynamic stresses. 184 This suggests that in some cases damage and off-fault deformation reflect rock failure associated 
185 with different processes and scales, and therefore here we do not use the two terms 186 interchangeably.

\subsection{Regional Tectonics and outstanding questions}

190 Why the major faults in the ECSZ do not intersect or displace one another has been a long-standing 191 problem because the kinematic evolution of fault junctions is not clear over long-term, geologic 192 timescales. (Andrew and Walker, 2017; Frankel et al., 2008; Oskin and Iriondo, 2004; Oskin et al., 193 2008). For example, none of the major NW-trending dextral faults in the Mojave ECSZ (e.g., the 194 Blackwater, Gravel Hills, North Lockhart and East Goldstone Lake faults, see Figure 1a and 6e) 195 continue northward to intersect or displace the central Garlock fault (Andrew and Walker, 2017).

196 The same can also be found at the southern margin of the Mojave Desert for the sinistral Pinto 197 Mountain fault near the southern termination of the 1992 Landers rupture (Sieh et al., 1993). 198 Numerical modeling and long-term geologic structural evidence indicate that dextral strain likely 199 transitions to distributed off-fault deformation beyond fault tips (Andrew and Walker, 2017; 200 Herbert et al., 2014). Paleomagnetic studies in this region have provided constraints of the rotation 201 of panels of crustal blocks associated with regional-scale bookshelf faulting, finding rotations of 202 up to $\sim 40^{\circ}$ over the past $\sim 10 \mathrm{Ma}$ (Schermer et al. 1996; Miller and Yount, 2002). However, there 203 are an insufficient number of paleomagnetic measurements that constrain the spatial distribution 204 and magnitude of rotations beyond the tips of NW-trending dextral faults to understand how the 205 long-term elastic strain is released at the junctures with conjugate sinistral faults. Here, we seek to 206 provide measurements of coseismic finite strain and rotations along the Ridgecrest rupture to 207 understand how dextral shear strain may transition to rotation beyond fault tips and whether this 208 can explain why the major conjugate faults in this region do not physically connect.

210 To answer the questions outlined above we used optical image correlation to, i) measure the 2D 211 dilatational, shear and rotational components of horizontal strain across different transpressional 212 and transtensional geometrical bends of the surface rupture and ii) asses how the width of the fault 213 zone varies according to the magnitude of extension and contraction it experiences. To provide 214 more robust estimates of how the inelastic strain decays as a function of distance from the primary 215 fault trace we developed a template-based stacking method that minimizes smoothing of 
216 displacement across the rupture, and we attempt to correct for the effect of smearing of the

217 displacement signal caused by the convolution of the correlation window weighting function that

218 arises during image matching. From the 2D displacement field we derive 2D finite strain maps and

219 the infinitesimal vertical axis rotations to understand the kinematics of faulting along the rupture

220 at the local and regional scale (10 and $100 \mathrm{~km}$ scale, respectively). We then use the strain and

221 rotation maps to understand the mechanisms by which some faults in the ECSZ do not intersect or

222 displace the Garlock fault, and the possible origin of cross-faulting and aftershock distributions

223 given they are mechanically contradictory to conventional Mohr-Coulomb failure criteria.

\section{2. Data \& Methods}

To measure the coseismic surface deformation we used subpixel image correlation of two optical SPOT-6 images that were acquired on September 15th, 2018 and July 24th, 2019 and therefore capture surface motion of both the foreshock and mainshock events. The SPOT images have a 60 $\mathrm{km}$ footprint and resolution of $1.5 \mathrm{~m}$, with almost the same incidence angles $\left(9.57^{\circ}\right.$ and $9.55^{\circ}$ for the pre- and post-images respectively), which helps minimize topographic distortions that can arise

232 from the parallax effect between different viewing geometries. To co-register, orthorectify and 233 correlate the before and after images we used the COSI-Corr software (Leprince et al, 2007). The

234 images are orthorectified using the satellite ancillary information which describes the exterior 235 orientation (i.e., look angle, attitude and satellite position) and a $2 \mathrm{~m}$ pre-earthquake World-View 236 DEM to correct for topographic distortions (Willis et al., 2019). The orthorectified and co237 registered images were then correlated using COSI-Corr's phase correlator with a sliding window 238 of $32 \times 32$ pixels and step of 4 pixels, producing a disparity map of the horizontal surface 239 displacement at $6 \mathrm{~m}$ resolution (Figure 1, see supplements S1 for details on noise of the result and 240 image artifacts).

242 To measure the total fault-parallel offset and decay of inelastic fault-parallel shear strain across 243 the surface rupture first requires projecting the 2D displacement maps (Figure 1) into the local 244 fault-parallel direction and then stacking over the profile swath width to minimize the effect of 245 noise. Here we have developed a new stacking profile method that provides a more accurate 246 estimate of the distribution of fault-parallel surface motion across the rupture over standard profile 
stacking approaches. Conventional stacking averages the fault-parallel motion along a constant

248 direction over the profile swath width. However, this can be problematic as it ignores variations

249 of the fault orientation within the profile swath that can lead to averaging of surface motion from

250 either side of the fault, which results in smoothing of the displacement distribution, artificial

251 widening of the fault zone and underestimation of the fault-parallel shear strains (see Figure S1

252 comparing conventional stacking versus our approach). To avoid this issue, we have developed a

253 subpixel template alignment stacking method, which first aligns each individual profile line with

254 subpixel precision prior to stacking. This is achieved by first creating a template from an initial

255 stack that is then cross-correlated with each individual profile line (here we use an along-fault

256 swath width of $138 \mathrm{~m}$ and across-fault profile length of 1-2 $\mathrm{km}$, which includes 23 separate 'profile

257 lines'). The optimal lateral shift to align each individual profile line is found with subpixel

258 precision by determining the peak of an outlier-resistant cross correlation coefficient. Once the

259 surface displacements are stacked with this approach, the total magnitude of the fault-parallel

260 offset (i.e., the total amplitude of the discontinuity shown in Figure S2 and S13) is then estimated

261 by inverting the fault-parallel displacements $(y)$, which are a function of the distance across the

262 profile $(x)$, for the coefficients of a linear and error function (eq. 1 and 2).

$$
\begin{gathered}
y(x)=a+\frac{b}{2} \cdot \operatorname{erf}\left(\frac{x-c}{w_{s} \sqrt{2}}\right)+\varepsilon_{e l} \cdot x \\
\operatorname{erf}(z)=\frac{2}{\sqrt{\pi}} \int_{0}^{z} e^{-t^{2}} d t, \quad z=\frac{x-c}{w_{s} \sqrt{2}}
\end{gathered}
$$

274 distribution (i.e., the derivative of eq. 2), which is opposite in sign to the elastic strain. Therefore,

275 the variation of the fault-parallel shear strain $\left(\varepsilon_{f p}\right.$, eq. [3]) across the fault zone can be expressed

276 as the summation of the inelastic strain $\left(\varepsilon_{\text {inel }}\right)$ and the fault-parallel elastic strain $\left(\varepsilon_{e l}\right.$, see Figure

277 S13), which is given by the following relation using the chain rule: 


$$
\varepsilon_{f p}(x)=\varepsilon_{\text {inel }}+\varepsilon_{e l}
$$

In the displacement profiles (eq. 1), the elastic strain in the near-field is approximated by a linear trend. We find this is reasonable given our profiles only sample the elastic dislocation signal within a short distance from the fault $(\leq 1 \mathrm{~km})$ compared to the length scale at which the elastic signal varies, that follows $\arctan (x)$ and is proportional to the depth extent of fault slip (Scholz [2019]), which for Ridgecrest is $10-15 \mathrm{~km}$. In addition, other sources of noise such as satellite jitter and orbit artifacts affect surface motion at longer length scales $(>1 \mathrm{~km}$, see section $\mathrm{S} 1)$ and therefore the estimated far-field gradient $\left(\varepsilon_{e l}\right)$ from these displacement maps offers limited constraint of slip at seismogenic depths.

292 From the 2D displacement maps we calculate the finite surface strain and local infinitesimal 293 rotations. We first apply a non-local means filter to reduce the effects of noise and then calculate 294 the spatial gradients of the displacement field using a second-order accurate central difference 295 approximation. Here we use the 2D displacement field $u_{d}(i, j)$ that is the output of the image correlation (Figure 1), where subscript $d$ is the change of position between the pre and post-event 297 satellite images in the east-west direction (denoted by subscript $x$ ) and north-south direction 298 (denoted by subscript $y$ ), where $i, j$ denote the indices of the displacement field in the $x$ and $y$ axes 299 and $\Delta x$ is the displacement map resolution $(6 \mathrm{~m})$. For example, the gradient of the east-west 300 component of displacement in the $x$ direction is calculated using the following finite difference 301 approximation:

$$
\frac{\Delta u_{x}(i, j)}{\Delta x}=\frac{u_{x}(i+1, j)-u_{x}(i-1, j)}{2 \Delta x}
$$

305 Calculating the gradients of the displacement components $\left(u_{x}, u_{y}\right)$ in the $x, y$ directions gives the 306 displacement gradient tensor, D , 


$$
\mathbf{D}=\left[\begin{array}{ll}
\left(\frac{\Delta u_{x}}{\Delta x}\right) & \left(\frac{\Delta u_{x}}{\Delta y}\right) \\
\left(\frac{\Delta u_{y}}{\Delta x}\right) & \left(\frac{\Delta u_{y}}{\Delta y}\right)
\end{array}\right]
$$

309 To calculate strain we use the Lagrangian finite strain tensor (E) instead of the typical infinitesimal 310 strain tensor because the condition of small strain is not met when resolving large strains across 311 the surface rupture (which can exceed 1\% strain in most cases, see supplements where we show 312 the differences between the two strain approximations in Figure S2), and is calculated from the 313 following relation using Einstein summation convention,

$$
\begin{gathered}
\mathbf{E}=\left[\begin{array}{ll}
E_{x x} & E_{x y} \\
E_{y x} & E_{y y}
\end{array}\right] \\
E_{i j}=\frac{1}{2}\left(\frac{\Delta u_{i}}{\Delta x_{j}}+\frac{\Delta u_{j}}{\Delta x_{i}}+\frac{\Delta u_{k}}{\Delta x_{i}} \frac{\Delta u_{k}}{\Delta x_{j}}\right)
\end{gathered}
$$

317 To measure contraction and extension along the rupture we calculate the dilatation (i.e., areal 318 strain) from the product of the principal stretches $\left(1+E_{i}, i=1,2\right)$, where positive values denote 319 extension and negative values contraction (Ramsay, 1967). To illustrate areas with different senses 320 of shear and to measure the infinitesimal rotations of regions away from the faulting regions we 321 calculate the vorticity $(\omega)$ of the vector field, which is also defined as half the curl $(c)$.

$$
\omega=\frac{c}{2}=\frac{1}{2}\left(\frac{\Delta u_{x}}{\Delta y}-\frac{\Delta u_{y}}{\Delta x}\right)
$$

323 We note that the vorticity is used primarily to measure the amount of instantaneous local vertical 324 axis rotation of blocks away from faults (which has units of radians) or to illustrate the rotational 325 component of surface motion associated with simple shear strain but it does not measure the shear 326 strain component of simple shear (where $\omega$ is defined as half the difference of the off-diagonal 327 components of the displacement gradient tensor [i.e., eq. 8] while the shear strain is the 328 summation). To help illustrate the variation of the total magnitude of strain along the surface 329 rupture we estimate the second invariant of the strain tensor $\left(I_{2}\right)$, which we call the total strain 330 intensity and can be computed from the determinant of $\mathbf{E}$ or, 


$$
I_{2}=\frac{1}{2}\left([\operatorname{tr}(\mathbf{E})]^{2}-\operatorname{tr}\left[\mathbf{E}^{2}\right]\right)
$$

332 The fault zone width is measured from each profile as the average width where the square root of

$333 I_{2}$ exceeds a threshold value of $2 \times 10^{-3}$ which corresponds to $0.2 \%$ of the shear strain intensity 334 and is an amount that corresponds to faulting observed in the field (Ponti et al., 2019; DuRoss et 335 al., 2020).

$337 \quad 3$ Results

\section{$338 \quad 3.1$ Distribution of Inelastic Strain}

The left-lateral slip distribution of the foreshock rupture shows a simple asymmetric triangular shape, while the right-lateral distribution of the mainshock is heterogeneous and multi-peaked

342 (Figure 2b). These along-strike variations of slip at different length scales (from 1-10 km) are 343 robust as indicated by the uncertainty in our measurements and may reflect variations due to the 344 fault geometrical roughness and strength or applied stress (Dunham et al., 2011; Shi and Day, 345 2013; Milliner et al., 2016; Allam et al., 2019; Bruhat et al., 2020). These variations can provide 346 useful constraints for the degree of aleatory variability of displacement along a rupture that inform 347 scaling relations in probabilistic fault displacement hazard models (Lavrentiadis \& Abrahamson, 348 2019). In addition, the total strain intensity map clearly shows changes of the total strain 349 magnitude (Figure 3a), which correspond to variations of the fault geometry and orientation along 350 the rupture. The total strain intensity is generally largest at the center of fault segments and 351 systematically decreases towards their tips in areas of fault bends, branches or en-echelon steps. 352 Along the foreshock rupture we find the mean and maximum left-lateral fault displacements of $3530.60 \pm 0.03 \mathrm{~m}$ (all uncertainties represent 1 standard deviation error, $1 \sigma)$ and $1.40 \pm 0.07 \mathrm{~m}(1 \sigma)$, 354 respectively, and for the mainshock rupture the mean and maximum right-lateral displacements of $3551.69 \pm 0.06 \mathrm{~m}(1 \sigma)$ and $4.78 \pm 0.22 \mathrm{~m}(1 \sigma)$, respectively (Table 1$)$.

We estimate the magnitude of OFD along both ruptures as the percent of the total displacement that is not accommodated on the primary coseismic fault strand. OFD is estimated by subtracting 359 the field observations $\left(D_{f}\right)$ (Ponti et al., 2019; DuRoss et al., 2020), which are assumed to capture 360 the primary on-fault displacement, from the total displacement estimated by our optical stacked 
361 profiles (which captures both the on- and off-fault deformation across the entire fault zone $\left[D_{o}\right]$ ) 362 which is then normalized by $D_{o}$, i.e., OFD $=\left[\left(D_{o}-D_{f}\right) / D_{o}\right] \times 100$. Normalizing the difference of 363 the total and on-fault displacements (measured in meters) by $D_{o}$, allows for a more direct 364 comparison of the amount of off-fault strain between the two ruptures which have different 365 moment magnitudes and amounts of total slip. From this comparison we find OFD is largest near 366 both terminations of the mainshock rupture (see Figure 2 for comparison and Figures S3 and S4) 367 and is overall much larger for the foreshock (mean and median values of $56,65 \pm 15 \%, 1 \sigma$ ) than 368 the mainshock (mean and median values of $34,25 \pm 15 \%, 1 \sigma$ ), which have negatively and 369 positively skewed distributions, respectively (Figure S5). The foreshock and mainshock rupture 370 strands show similar fault-zone widths, with mean values of $59 \pm 17 \mathrm{~m}(1 \sigma)$ and $69 \pm 23 \mathrm{~m}(1 \sigma)$, 371 respectively (Figure S6).

373 The 2D strain maps show that the dilatational component of strain is largest at changes in the 374 geometry of the rupture (Figure $4 b$ ), where for example, extensional strain (positive dilatation) is 375 largest at sites of right transtensional fault bends. Along curvilinear segments, where there are 376 subtle changes in the fault orientation, the sign of dilatation varies from negative (contraction) to 377 positive (extensional) over short $\sim 100 \mathrm{~m}$ distances that correspond to subtle restraining and 378 releasing bends of the fault (bottom right of Figure $4 \mathrm{~b}$ along segment $\mathrm{i}$ ). To understand how the 379 width of the fault zone may vary according to the type of strain the fault experiences, we compare 380 the fault zone width measurements along the mainshock rupture from within the transtensional 381 bend (segment ii in Figure 4a) to a linear segment adjacent to it that experienced predominantly 382 shear (segment i). Comparison of the distributions of the fault zone widths between these two 383 neighboring segments shows a clear statistical difference (Figure S6). A one-tailed t-test shows 384 that we can reject at the 5\% confidence level that the two distributions of fault zone width have 385 the same mean value between these two fault segments, indicating there are significantly wider 386 fault zones within the transtensional bend (segment ii) undergoing tension than along the linear 387 segment (segment i) that experienced mostly shear strain.

389 To understand a possible dependency of the fault zone width with the magnitude of contraction 390 and extension the fault zone experiences we regress the measured fault zone widths from two km391 scale right bends, a linear segment between these bends (Figure 4a) and two short transpressional 
392 bends (see green boxes in Figure $1 \mathrm{~b}$ for locations) with the magnitude of dilatation. Here we find 393 wider fault zones along the transpressional and transtensional segments and narrowing in regions 394 of decreasing dilatational strain (Figure 5a). To describe this dependency, we use a segmented 395 regression analysis, which is a model choice supported by an F-test that shows a piecewise linear 396 function provides a better fit over a linear one even when considering the effect of additional model 397 parameters. Unfortunately, as there are simply not enough transpressional segments or restraining 398 bends along the rupture we are unable to better populate the negative dilatation quadrant in our 399 regression analysis (left side of Figure 5a). In addition, as illustrated by the wide $95 \%$ confidence 400 interval bands we do not have sufficient constraint to test with confidence whether fault zones are 401 wider under extension than contraction. Another limitation of the analysis is that due to the sparsity 402 of field measurements along the transtensional segment (segment ii in Figure 4b) there are an 403 insufficient number of OFD points (shown in Figures S3 and S4) to assess how the magnitude of 404 distributed inelastic shear strain may scale with the degree of fault zone dilatation.

406 We also find a difference of the spatial distribution of deformation across the fault zone between 407 the types of different fault geometries. This can be seen when comparing strain profiles across the 408 transtensional bend (segment ii, Figure $4 \mathrm{~b}$ ) to the adjacent more linear rupture segment to the south 409 (segment i). These profiles show a clear difference in how the inelastic dilatational and shear 410 components of strain decay with distance away from the primary rupture between these two 411 segments (Figure 5c). This suggests that not only can the differences in width of fault zones be 412 resolved (a scalar quantity) but also the spatial distribution of inelastic strain across segments of 413 different geometries.

415 The effect of the foreshock rupture on the distribution of strain across and along the mainshock 416 rupture can also be clearly observed at the site where they intersect using the displacement, 417 vorticity and dilatational strain maps (Figure 3). The dilatational strain field shows that the 418 mainshock rupture experienced extension on the segment northwest of the intersection and 419 contraction southeast of the intersection (Figure 3d), which is consistent with the expected location 420 of unclamping and clamping, respectively, due to static stress changes imposed by slip along the 421 foreshock rupture (e.g., Barnhart et al., 2019; Wang et al., 2020; Chen et al., 2020). In addition, 422 we find a noticeable increase of the vorticity along the mainshock rupture that experienced positive 
423 dilatation (unclamping) and a decrease relative to the segment that experienced negative dilatation 424 (clamping) (which are labelled i) and ii) in Figure 3c). These differences in the amount of rotation 425 between the two segments suggests a possible increase in the intensity of simple shear strain but 426 this is not definitive evidence as the vorticity only captures the rotational component of simple 427 shear. Therefore, to verify this we found from displacement profiles across the mainshock rupture 428 that there is indeed a $20 \mathrm{~cm}$ increase of the total fault-parallel displacement from the clamped to 429 the unclamped segment (Figure 3f). Profiles that measure the fault-perpendicular surface motion 430 (Figure 3g) also clearly show the two fault mainshock rupture segments either side of the 431 intersection experienced clamping (with a total of $50 \mathrm{~cm}$ of differential surface motion converging 432 across the fault) and unclamping (a total of $40 \mathrm{~cm}$ of differential surface motion diverging away 433 from the fault).

\subsection{Bookshelf kinematics}

Near the northern termination of the mainshock rupture the vorticity map shows a series of faults 438 that are orthogonal to the main trend of the mainshock rupture that produce a symmetrical 439 'hourglass' shape (Figure 6). The vorticity maps reveal a series of parallel, NE-trending sinistral 440 shear zones (red regions), that are bracketed to the southeast and northwest by conjugate and 441 almost orthogonally orientated NW-trending dextral faults (blue regions). Between the series of 442 parallel sinistral faults are zones of relatively large negative vorticity (blue regions in Figure 6a, 443 also see $7 \mathrm{a}, \mathrm{b})$. We note that the vorticity cannot differentiate between rotations and distributed 444 fracturing, but due to the pervasive distribution of these high vorticity values and the lack of 445 observed distributed fracturing from field surveying (depicted as black lines in Figures 6a and 7a), 446 the regions between the main faults are likely indicative of block rotations of up to $\sim 0.12^{\circ}$. These 447 types of kinematics are indicative of bookshelf faulting, where the conjugate faults and intra-fault 448 block rotations act to collectively accommodate regional dextral shear (McKenzie and Jackson, 449 1983; Wesnousky, 2005). The different mechanisms by which the regional dextral shear is released 450 can be seen first in the center of Figure 6a, where the total right-lateral shear is accommodated by 451 a single dextral fault strand with a total offset $\sim 1.6 \mathrm{~m}$, this offset is then partitioned further south 452 between three parallel dextral fault strands, and then partitioned again further south amongst the 453 conjugate sinistral faults and clockwise rotating blocks (Figure 6a and 7a, b). 
To determine whether the observed kinematics of the co-seismic ruptures are consistent with the longer-term pattern of cumulative shear and rotation expected by bookshelf kinematics which has been found to describe the longer-term pattern of faulting elsewhere in nearby regions (e.g., McKenzie and Jackson, 1983; Ron et al., 1984; Wesnousky, 2005), we compare the surface motions measured in our displacement and vorticity maps to the kinematic relations of a bookshelf fault system (McKenzie and Jackson, 1983; Platt and Becker, 2013). If the regional right-lateral shear displacement $(\gamma)$ and the angle between the conjugate and bounding faults $(\alpha)$ are known, then the amount of sinistral slip along the array of conjugate faults $\left(\gamma^{\prime}\right)$ expected from bookshelf faulting can be estimated from the following geometric relation (also see inset of Figure 6c).

$$
\gamma^{\prime}=\gamma \cdot \cos (2 \alpha)
$$

The rotation of the blocks $(\omega)$ can be estimated from eq. 11 and assuming horizontal plane strain, a component of contractional or extensional strain normal to the fault blocks $(e)$ can be estimated from eq. 12 , where $l_{b}$ is the block length.

$$
\omega=\frac{\gamma}{2} \cdot(1-\cos [2 \alpha])
$$

$$
e=-\frac{\gamma}{2 l_{b}} \cdot \sin (2 \alpha)
$$

474 From these relations and measuring $\gamma=1.6 \mathrm{~m}$ and $\alpha=66^{\circ}$ (from Figure 6a) this predicts $\gamma^{\prime}=1.0$ $475 \mathrm{~m}, e=0.044 \%$ strain and $\omega=0.05^{\circ}$ (see Table 2 ). These predicted values compare well with those 476 observed from the strain and displacement maps (Figure 6a and 7), where we find $\gamma^{\prime}=0.8 \mathrm{~m}$ 477 (measured from the southernmost sinistral fault), $e=0.04 \%$ strain (measured from within the 478 bookshelf blocks, see Figure S7) and $\omega=0.06^{\circ}$ (mean value estimated from within the 479 southernmost 'block' in Figure 6), which show the observed kinematics are consistent with 480 bookshelf faulting.

482 To test whether the foreshock and mainshock cross-faulting are a larger-scale version of the same 483 bookshelf tectonics shown in Figure 6a and c, we again use the kinematic bookshelf relations to 
484 compare its predictions against the observed displacements at the macroscopic scale (McKenzie 485 and Jackson, 1983; Platt and Becker, 2013). From measuring the mean slip along the mainshock 486 strand immediately adjacent to the foreshock strand we find $\gamma=0.98 \mathrm{~m}$ and the angle between the 487 mainshock-foreshock strands is $\alpha=86^{\circ}$. From this we find the predicted slip on the foreshock fault 488 is $\gamma^{\prime}=0.97 \mathrm{~m}$ which falls within the variation of observed values (mean observed sinistral 489 displacement of $0.71 \pm 0.33 \mathrm{~m}, 1 \sigma$, and maximum of $1.40 \mathrm{~m}$, Figure 2 ).

We can also estimate the total amount of long-term cumulative displacement $\left(d_{\text {fore }}\right)$ accrued along the conjugate sinistral foreshock fault (the strand west of the mainshock strand) since its initiation. To do this we use a simple geometric expression that relates $d_{f o r e}$ to the amount of total block rotation that has occurred across a zone of simple shear (Freund, 1974; Ron et al., 1984). Assuming only plane strain, $d_{\text {fore }}$ is related to: the width of fault-bounded blocks ( $w_{b}$, see Figure $\left.6 \mathrm{c}\right)$, the initial angle between the conjugate faults when they first formed $\left(\alpha_{i}\right)$ and the total amount of rotation since they formed $\left(\omega_{T}\right)$ as defined by the following relation (Freund, 1974; Ron et al., 1984),

$$
d_{\text {fore }}=w_{b}\left[\frac{\sin \left(\omega_{T}\right)}{\sin (\alpha) \cdot \sin \left(\alpha-\omega_{T}\right)}\right]
$$

The width of the block $\left(w_{b}=4.89 \mathrm{~km}\right)$ is measured as the distance between the foreshock fault west of the mainshock strand to another parallel SW-trending fault to the south (see Figure 6c). This gives an aspect ratio of the crustal block (width/length) of 0.37 which is consistent with the aspect ratios of the smaller blocks in Figure 6a, that have a mean value of $0.35(n=5)$. The total amount of rotation of the foreshock fault $\left(\omega_{T}=3-7^{\circ}\right)$ is estimated from the difference of its average azimuth $\left(\mathrm{N} 43^{\circ} \mathrm{E}\right)$ with the azimuth of the smaller conjugate sinistral faults shown in Figure 6a (with minimum and maximum values ranging from $\mathrm{N} 36-40^{\circ} \mathrm{E}$ ). This assumes that the much shorter 508 sinistral faults (ranging in lengths from $200-1300 \mathrm{~m}$ ) shown in Figure 6a are close to their initial orientation when they developed. The initial angle between the conjugate foreshock faults and the

510 bounding dextral mainshock faults is assumed as $\alpha=90^{\circ}$ (a value also used for conjugate faults 511 further north in the Walker Lane [see Wesnousky, 2005]). This gives $d_{\text {fore }}=256-600 \mathrm{~m}$, which 512 indicates that the foreshock fault is highly structurally immature. 


\section{Discussion}

\subsection{Effect of Off-fault Deformation on Rupture}

518 Experimental and theoretical studies show that the rupture propagation through the near-surface

519 ( $<5 \mathrm{~km}$ depth) can be inhibited by a range of mechanisms, including velocity-strengthening 520 frictional properties of the sliding fault in the near-surface, generation of plastic strain during 521 rupture, and frictional sliding on pre-existing fractures that can dissipate the rupture energy (Fialko 522 et al., 2005; Sammis et al., 2010; Kaneko and Fialko, 2011; Gabriel et al., 2013). These 523 mechanisms may explain why some earthquakes exhibit significantly lower slip at the surface than 524 at seismogenic depths $(6-10 \mathrm{~km})$, which has been termed the shallow slip deficit (Fialko et al., 525 2005), and why ruptures with faster velocities are observed along more mature structurally 526 developed smoother faults, e.g., the $1999 \mathrm{M}_{\mathrm{w}} 7.4$ Izmit, $2001 \mathrm{M}_{\mathrm{w}} 7.8$ Kokoxili, $2002 \mathrm{M}_{\mathrm{w}}$ 7.9 Denali 527 and $2018 \mathrm{M}_{\mathrm{w}}$ 7.5 Palu earthquakes (Bouchon et al., 2001, 2010; Ozacar and Beck, 2004; Bao et 528 al., 2019; Socquet et al., 2019).

530 As faults accumulate displacement over geologic timescales, they are thought to evolve or 'mature' progressively from a network of disorganized and disconnected segments that are separated by geometrical complexities (such as stepovers, bends and branches), to a structurally simplified 533 system or sometimes single throughgoing fault (Tchalenko, 1970; Wesnousky, 1988; Stirling et 534 al., 1996). This structural evolution can occur via a range of fault growth and strain weakening 535 feedback processes (Ben-Zion \& Sammis, 2003; Faulkner \& Mitchell, 2011). A consequence of 536 this evolutionary process is that as strain progressively localizes to the fault core, distributed 537 fractures become abandoned (Frost et al., 2009). This is manifest by a decreasing density of 538 stepovers at the macroscopic scale (Wesnousky, 1988) and decreasing amounts of distributed off539 fault inelastic strain (Dolan and Haravitch, 2014). Here we find OFD for the foreshock is much 540 larger than the mainshock (56\% and 34\% respectively), which we interpret as indicating the faults 541 involved in the foreshock rupture have a lower degree of strain localization and are therefore less 542 structurally developed (Dolan and Haravitch, 2014). To support this inference, we have assessed 543 a number of other relevant factors, which includes both qualitatively and quantitatively comparing 544 the geometrical fault complexity of the foreshock to the mainshock. First, surface rupture mapping 
545 from daily Planet Labs imagery, which can uniquely separate the two events in time (Milliner \& 546 Donnellan, 2020), show the foreshock is clearly more structurally complex with a higher number 547 of disorganized segments (see Figure S8). Second, from estimating the density of major stepovers 548 (with $>1 \mathrm{~km}$ width, following the approach of Wesnousky [1988]) we find it is almost a factor of 549 two higher for the foreshock (0.157 stepovers/unit length) than the mainshock (0.08), again 550 showing the foreshock involved a more disconnected fault system. Lastly, measurements of offset 551 Late Jurassic dikes across the southern end of the Ridgecrest mainshock rupture found a 552 cumulative displacement of $1.6 \mathrm{~km}$, although there are no available geomorphic features to 553 estimate a value across the foreshock rupture (Andrew \& Walker, 2020). However, this value of $554 \quad 1.6 \mathrm{~km}$ is much larger than our estimated cumulative displacement for the faults involved in the 555 foreshock rupture of 256-600 m, suggesting a clear difference in the structural maturity. Although 556 there is not a known independent estimate of the cumulative displacement for the foreshock rupture 557 to verify possible differences in the relative structural maturity of the faults involved in the two 558 ruptures, our results do show clear differences in the degree of strain localization, structural 559 organization and significant differences in estimates of the cumulative displacement assuming 560 bookshelf type kinematics.

562 Here, we assess whether faults that have larger OFD (i.e., larger amounts of distributed inelastic 563 strain and are therefore likely less mature), have slower rupture velocities and more pronounced 564 shallow slip deficits. The mean OFD measured along the mainshock rupture $(34 \pm 10 \%)$ is similar 565 in magnitude to that measured along other nearby surface ruptures including the $1992 \mathrm{M}_{\mathrm{w}} 7.3$ 566 Landers and $1999 \mathrm{M}_{\mathrm{w}} 7.1$ Hector Mine events (which had OFD of $46 \pm 10 \%$ and $39 \pm 22 \%$, 567 respectively, which we note were estimated using the same field-optical displacement comparison 568 approach [Milliner et al., 2016]), and are fault systems that are known to be immature (with 3-4 $569 \mathrm{~km}$ of cumulative displacement [Jachens et al. 2002]). Interestingly, all three of these relatively 570 immature NW-trending dextral fault systems exhibit relatively similar slow rupture velocities of $571 \sim 2.7 \mathrm{~km} /, 2.2 \mathrm{~km} / \mathrm{s}$, and $2 \mathrm{~km} / \mathrm{s}$ for the Landers, Hector Mine and Ridgecrest events, respectively 572 (Chen et al., 2020; Goldberg et al., 2020; Ji et al., 2002; Liu et al., 2019; Peyrat et al., 2001; Ross 573 et al., 2019), consistent with the notion that slower ruptures occur along faults of higher OFD with 574 more complex multi-segment rupture geometries. 
576 The larger amount of OFD found for the foreshock (56\%) than the mainshock rupture $(34 \%)$, 577 provides another and more direct means to compare the possible effect of off-fault distributed strain on the shallow slip deficit and rupture velocity. Current seismic inversion models of the rupture do not show a significant difference of the velocity between the two events, finding they are both $\sim 2 \mathrm{~km} / \mathrm{s}$ (Chen et al., 2020; Goldberg et al., 2020; Ross et al., 2019; Wang et al., 2020). However, the lack of a resolvable difference could result from limitations of the inversion method such as the model resolution, data constraints and sensitivity, or inherent trade-offs (e.g., see Figure S4 of Chen et al., 2020 for the range of possible velocities). An additional complication is that it is possible the mainshock rupture velocity could have been inhibited by a decrease of static Coulomb stress applied by the foreshock rupture, as high shear pre-stresses along faults are thought to cause faster rupture velocities (Bao et al., 2019). However, this effect of reduced pre- shear stress is likely to be small in this case, given slip inversion models estimate a minor change $(\sim-0.2$ $\mathrm{MPa}$ ) compared to the total stress drop (10 MPa), (Barnhart et al., 2019; Chen et al., 2020). Therefore, it is not immediately clear if the rupture velocities between the foreshock and mainshock are significantly similar or not, or the effect of local pre-stress changes, which complicates understanding the effect of OFD on the efficiency of rupture propagation.

To assess differences in the variation of slip with depth between the $M_{w} 6.4$ foreshock and $M_{w} 7.1$ mainshock events we compiled slip distributions from four available geodetic and seismic slip inversion studies (Chen et al., 2020; Jin and Fialko, 2019; Xu et al., 2020; Wang et al., 2020). Although there is a wide variation of the slip-depth distributions between the various slip inversion models, which reflects the epistemic uncertainty due to varying model parameterizations, inversion strategies and data types, there are still systematic differences between the foreshock and 599 mainshock events (Figure 8). Estimating the shallow slip deficit as the percent difference of surface 600 slip to the maximum at depth, we find a more pronounced shallow slip deficit for the foreshock 601 (ranging from 42-65\%) than the mainshock (18-35\%), consistent with the notion that more 602 immature faults that exhibit larger amounts of inelastic strain (i.e., OFD) correspond to larger 603 shallow slip deficits (as proposed by Kaneko \& Fialko, 2011). In contrast, the shallow slip deficit 604 estimates of the 1992 Landers and 1999 Hector Mine events from geodetic inversions show much 605 smaller values at $18 \%$ and 3\%, respectively (Xu et al., 2016). The apparent similar amounts of 606 inelastic strain (34\%, 46\% and 39\% OFD) but differing shallow slip deficits (18-35\%, 18\%, and 
$6073 \%$ ) between these three large events (Ridgecrest, Landers and Hector Mine, respectively) 608 conflicts with the expectation that the former may influence the latter. This may suggest the 609 importance of other processes in affecting the efficiency of rupture propagation through the near610 surface such as sediment thickness and type, pre-stress on the fault, frictional properties, or 611 dilatancy strengthening (Rice, 1975; Marone et al., 1991; Kaneko and Fialko, 2011; Dolan and 612 Haravitch, 2014).

\subsection{Inelastic strain and the effect of fault zone dilatation}

From comparison of the measured fault zone width with the dilatational component of the 2D

617 strain tensor we find that both the scalar width and decay rate of inelastic strain away from the 618 main rupture are wider and slower in regions of extension and contraction than shear (Figure 5).

619 We find that the magnitude and sense of dilatational strain (i.e., contraction or extension), varies

620 according to the fault geometry and orientation, with extensional strain expectedly largest along 621 releasing fault bends (Figures 3 and 4). This is consistent with previous work that have found 622 correlations of the scalar fault width or OFD with the fault geometry along oblique-normal strike623 slip faults (Scott et al., 2018; Teran et al., 2015). Along the Ridgecrest rupture we have shown that 624 these geometries alter the type of strain the fault zone experiences and that such strain is partitioned 625 differently between the shear and dilatational components (Figure $4 \mathrm{a}$ and $\mathrm{b}$ ).

627 Constraining how fast or slow inelastic strain decays away from the primary rupture holds 628 importance for better characterizing the hazard of distributed fault rupture, which is needed to 629 effectively engineer structures to withstand its effect (e.g., for roads, pipelines or bridges that 630 cannot avoid fault crossings). As more confidence is known of what parameters control the spatial 631 distribution of inelastic strain across a surface rupture (e.g., the type of fault geometry or sediment 632 thickness) through increasing observational constraint, this will help explain more of the total 633 variance of the fault zone width along the lengths of ruptures. In doing so this will reduce the 634 epistemic uncertainty of empirically constrained probabilistic fault displacement hazard models 635 and improve their predictive power (e.g., Petersen et al., 2011). For example, our results show that 636 transtensional bends have a different level of distributed rupture hazard, with a higher probability 637 of experiencing distributed rupture further away from the primary fault, than segments that 
experience predominantly shear strain (Figure $5 b$ and c). This would therefore justify developing separate fault displacement prediction equations for differing fault geometries into probabilistic fault displacement hazard analysis.

\subsection{Orthogonal faulting due to Bookshelf kinematics}

644 Bookshelf faulting is thought to initiate from simple shear being accommodated by conjugate pairs 645 of synthetic (R) and antithetic (R') Riedel shears across a trans-tensional step-over region 646 (Wesnousky, 2005). Over time, as the Riedel fractures accumulate slip, the primary en-echelon R 647 shears coalesce to form a single through-going fault strand, while the R' shears located within the 648 stepover are progressively rotated and become increasingly more oblique to the $\mathrm{R}$ shears, eventually forming a set of orthogonal faults. Here, we find that the observed displacements along the orthogonal set of faults involved in the foreshock and mainshock ruptures are consistent with the kinematics expected by bookshelf faulting indicating they are a larger scale, more-developed system of the bookshelf faulting observed at the smaller scale in Fig 6a and c. In addition, the asymmetric triangular distribution of slip along the foreshock rupture (at the $\sim 10 \mathrm{~km}$ scale) bears a strong similarity to that of slip along the smaller sinistral conjugate faults shown in Figure 6d (at the $\sim 100 \mathrm{~m}$ scale, also see Figure S9 for comparison). Such bookshelf faulting which involves progressive rotation of conjugate faults to orientations that become highly oblique could also explain the wide-spread distribution of orthogonal aftershocks at other length scales in this region 658 (Ross et al., 2019). A bookshelf system at the $\sim 10 \mathrm{~km}$ scale also suggests that the Little Lake and Airport Fault Zones (LLFZ and APFZ) would form the western-most bounding NW-trending dextral fault. This provides a possible explanation as to why the foreshock rupture terminated surprisingly at a site of peak slip in the southwest ( $1.4 \mathrm{~m}$, Figure 2$)$, simply because it is structurally controlled by the bookshelf kinematics; i.e., west of the LLFZ and APFZ there is likely 663 little-no rotations of crustal blocks which means sinistral slip is not kinematically required and 664 therefore the foreshock fault simply does not extend further west. However, one notable difference from the bookshelf initiation framework proposed by Wesnousky 667 (2005) is that the bookshelf faulting found specifically at the northern end of the mainshock rupture 668 (Figures 6 and 7) does not seem to occur within a transtensional step. Here there are clearly no 
669 dextral faults that extend to either side to 'bound' the sinistral faults that would satisfy the 670 definition of a stepover, nor does the rupture step to the right that would produce transtension and 671 the dilatation map shows no evidence of significant extension. Instead, the clockwise rotation and 672 sinistral faulting found here are located directly beyond the tips of and between three north-west 673 trending dextral faults (one to the north and the other two to the south), producing an 'hourglass' 674 geometry. We argue another possible mechanism in which bookshelf kinematics could arise is due 675 to the transition of shear strain to rotation beyond fault tips (like that shown by the vorticity map, 676 Figure 6a). In the case here, two or more faults do not align or connect, which creates a zone of 677 distributed clockwise rotation. For the dextral shear to be accommodated over a region (in this 678 case this is $\sim 2 \mathrm{~m}$ of dextral motion distributed over an $\sim 1.5 \mathrm{~km}$ wide zone across the 'bookshelf', 679 see Figure 7d) it can be shown that both clockwise rotation (illustrated in Figure 6a and 7d) and 680 perpendicular sinistral shear is required (shown in Figure 7c, where such strain is responsible for 681 producing the series of parallel sinistral fractures), as the summation of the displacement gradients 682 of both these types of surface motion are equivalent to dextral shear and does not require 683 transtensional strain (Platt, 2017). A similar behavior of bookshelf faulting was also observed from 684 relocated aftershocks of the $1986 \mathrm{M}_{\mathrm{L}} 5.7$ Mount Lewis earthquake, CA (Kilb et al. 2002). The 685 seismicity showed a series of orthogonal sinistral faults that were not located within a stepover but 686 instead directly beyond the tips of a dextral fault, which produced a similar 'hourglass' shaped 687 feature as observed here (also see Kim et al., 2004). For the kinematics found specifically at the 688 northern end of the Ridgecrest rupture, the cause of bookshelf faulting seems to be more consistent 689 with how shear strain transitions beyond fault tips to rotation (i.e., a type of fault termination 690 structure) than a result of distributed transtensional shear across a right-stepover which is a 691 mechanism more applicable to faulting within the Mina deflection further north in the Walker Lane 692 (Wesnousky, 2005).

693

694 We note that although the progressive rotation of faults over geologic timescales due to bookshelf 695 kinematics is one possible explanation for the occurrence of orthogonal faults into an unfavorable 696 orientation relative to the background stress state, lab and theoretical studies have shown that 697 during rupture the dynamic stresses locally along faults can rotate away from the far-field stresses 698 which can cause failure of faults with orthogonal geometries (Rousseau and Rosakis, 2003; Xu \& 699 Ben-Zion, 2013). Therefore, it is possible that both progressive rotation of faults over geologic 
timescales due to bookshelf kinematics and rotation of stresses locally along faults during rupture

701 could explain the generation and slip of orthogonal faults that are seemingly unfavorable with

702 respect to the regional, far-field, background stress state.

703

704 A number of major northwest trending dextral faults in the ECSZ seem to stop abruptly at major 705 orthogonally orientated sinistral faults (such as the Garlock or Pinto Mountain faults, see Figure 706 6e). The lack of a physical connection makes it unclear how the regional right-lateral shear strain 707 is accommodated across these fault gaps and how these junctions evolve over geologic timescales. 708 A lack of paleomagnetic data specifically at these fault gaps also make it difficult to understand 709 the role of crustal rotations in accommodating this long-term regional dextral strain. Here the 710 vorticity map shows clear regions of relatively large clockwise rotation adjacent to NE-trending 711 sinistral faults (Figure 6a). Observations from field mapping of the rupture do not show pervasive 712 fracturing in these regions, which confirms that much of the large negative vorticity values most 713 likely reflect crustal rotations (that range up to $\sim 0.1^{\circ}$ ). The vorticity map also shows that neither 714 the northern nor the southern set of conjugate sinistral faults (i.e., within either end of the 715 'hourglass' feature) intersect or displace the NW-trending dextral faults but are instead embedded 716 within regions of clockwise rotation. This provides one possible explanation as to why NW717 trending dextral faults do not physically connect with neighboring NE-trending sinistral faults, 718 simply because dextral brittle shear strain transitions beyond their tips to zones of clockwise 719 rotation as previously hypothesized (Andrew and Walker, 2017). As mentioned, dextral shear is

720 kinematically equivalent to the sum of surface motion from orthogonally orientated sinistral shear 721 and clockwise rotation (Platt, 2017). Therefore, our observations of coseismic strain release we

722 believe are analogous and support the kinematic argument that the remaining component of long723 term dextral strain across regions of fault gaps is likely accommodated by clockwise rotation that 724 explains the lack of a physical fault connection or continuation of local dextral strain (i.e., that 725 shown in Figure 6a).

\section{Conclusions}

729 Measurements of surface motion across the Ridgecrest surface rupture from high-resolution optical 730 image correlation provide empirical constraints of the effect of contraction and extension on the 
731 width of the fault zone. The results show that as expected, faults are clearly wider under extension

732 and contraction than lateral shear, but we are unable to discern whether they are wider under 733 extension than contraction. This relation also helps explain the apparent correlation of fault 734 geometrical complexities with wider faults zones, as variations of the fault orientation alter the 735 local stress state, causing fault-perpendicular strain that is not equally partitioned across the fault 736 zone between the dilatational and shear strain components. Observations of how the inelastic strain 737 attenuates with distance from the primary rupture (Figure. 4 b, c) also suggests there are different 738 hazard probabilities of distributed rupture for transpressional and transtensional bends compared 739 to simpler, more linear segments of the rupture that experience predominantly shear strain. We 740 suggest these differences could be accounted for by developing separate fault displacement 741 prediction equations for different fault geometries when incorporating them into probabilistic fault 742 displacement hazard analysis (PFDHA).

744 Our analysis shows that the faults involved in both the foreshock and mainshock ruptures are both 745 structurally immature and that the former is likely less structurally developed as we find a higher 746 amount of distributed inelastic strain (with average off-fault deformation amounts of $56 \pm 10 \%$ 747 and $34 \pm 10 \%$, respectively). The structural immaturity of the foreshock faults is also supported 748 by an estimate of its cumulative displacement, which is found from approximating the kinematics 749 to bookshelf motion, that gives a relatively low total amount of 250-600 m. The larger amount of 750 off-fault deformation and inferred lower structural maturity for the foreshock faults shows a fault 751 system with higher amounts of near-surface distributed inelastic strain and poorer fault linkage. 752 These are all thought to affect the efficiency of rupture propagation through the shallow surface, 753 which could explain why the foreshock rupture exhibits a higher slip deficit than the more mature 754 and structurally simplified mainshock rupture (Wesnousky, 1988; Kaneko \& Fialko, 2011; Dolan 755 and Haravitch, 2014).

757 We propose that bookshelf faulting provides a concise and useful framework to explain a number 758 of questions regarding the faulting kinematics of this region at the local and regional scale. Our 759 measurements of 2D strain and rotation show, i) faults do not intersect one another because dextral 760 strain transitions to clockwise rotation beyond their tips, ii) cross-faulting and aftershock 761 distributions arise because of a history of progressive clockwise rotation over geologic time of 
762 conjugate faults that accommodate simple shear, iii) the foreshock-mainshock ruptures are likely 763 a larger scale version of 'bookshelf faulting' which can explain the southwestern termination point 764 of the foreshock event because it structurally abuts the Little Lake fault zones that mark the west765 bounding 'bookshelf' fault.

\section{Acknowledgements}

We would like to thank the reviewers Chelsea Scott, Mike Oskin and Shiqing Xu for their helpful suggestions, and Cecile Lasserre and Isabelle Manighetti for their comments that helped strengthen and clarify aspects of our study. We also thank Alex Morelan, Tim Dawson, Kate Scharer, for their helpful discussions and sharing of data as well as the many field geologists who cannot all be mentioned here who provided the invaluable and detailed field survey measurements of the surface ruptures. Funding: Part of this research was supported by the NASA Earth Surface and Interior focus area and performed at the Jet Propulsion Laboratory, California Institute of Technology (80NM0018D0004). Funding for this project was provided under a NASA Postdoctoral Program fellowship to C.M. administered by the Universities Space and Research Association through a contract with NASA. Satellite imagery for this project were purchased under SCEC grant \#19222. Author contributions: All authors contributed to this study and participated in manuscript revision. Competing interests: The authors declare that they have no competing interests. Data and materials availability: Please see supplementary datasets or the Zenodo open repository (http://doi.org/10.5281/zenodo.3937853) containing measurements of the coseismic fault slip,

784 fault zone width and off-fault deformation

\section{References} coseismic slip and earthquake locations. Journal of Geophysical Research: Solid Earth. 2019 Nov; 124(11):11336-49 
Amos, C.B., Brownlee, S.J., Rood, D.H., Fisher, G.B., Bürgmann, R., Renne, P.R. and Jayko, A.S., 2013. Chronology of tectonic, geomorphic, and volcanic interactions and the tempo of fault slip near Little Lake, California. Bulletin, 125(7-8), pp.1187-1202.

Anderson, E.M., 1951. The dynamics of faulting and dyke formation with applications to Britain. Oliver and Boyd, Edinburgh.

Andrew, J.E., Walker, J.D., 2017. Path and amount of dextral fault slip in the Eastern California

Bouchon, M., Karabulut, H., Bouin, M.-P., Schmittbuhl, J., Vallée, M., Archuleta, R., Das, S., Renard, F., Marsan, D., 2010. Faulting characteristics of supershear earthquakes. 
823 Brandenberg, S.J., Stewart, J.P., Wang, P., Nweke, C.C., Hudson, K., Goulet, C.A., Meng, X.,

824 Davis, C.A., Ahdi, S.K., Hudson, M.B., Donnellan, A., Lyzenga, G., Pierce, M., Wang, J., Winters, M.A., Delisle, M.-P., Lucey, J., Kim, Y., Gallien, T.W., Lyda, A., Yeung, J.S., Issa, O., Buckreis, T., Yi, Z., 2020. Ground Deformation Data from GEER Investigations of Ridgecrest Earthquake Sequence. Seismol. Res. Lett. https://doi.org/10.1785/0220190291

Brooks, B.A., Minson, S.E., Glennie, C.L., Nevitt, J.M., Dawson, T., Rubin, R., Ericksen, T.L., Lockner, D., Hudnut, K., Langenheim, V., Lutz, A., Mareschal, M., Murray, J., Schwartz, D., Zaccone, D., 2017. Buried shallow fault slip from the South Napa earthquake revealed by near-field geodesy. Sci. Adv. 3, e1700525. https://doi.org/10.1126/sciadv.1700525

Bruhat L, Klinger Y, Vallage A, Dunham EM. Influence of fault roughness on surface displacement: from numerical simulations to coseismic slip distributions. Geophysical Journal International. 2020 Mar;220(3):1857-77.

Chen, K., Avouac, J.-P., Aati, S., Milliner, C., Zheng, F., Shi, C., 2020. Cascading and pulse-like ruptures during the 2019 Ridgecrest earthquakes in the Eastern California Shear Zone. Nat. Commun. 11, 22. https://doi.org/10.1038/s41467-019-13750-w

Dawson, T.E., McGill, S.F. and Rockwell, T.K., 2003. Irregular recurrence of paleoearthquakes along the central Garlock fault near El Paso Peaks, California. Journal of Geophysical Research: Solid Earth, 108(B7). doi.org/10.1029/2001JB001744

Dolan, J.F. and Haravitch, B.D., 2014. How well do surface slip measurements track slip at depth in large strike-slip earthquakes? The importance of fault structural maturity in controlling on-fault slip versus off-fault surface deformation. Earth and Planetary Science Letters, 388, pp.38-47.

Dolan, J.F., McAuliffe, L.J., Rhodes, E.J., McGill, S.F., Zinke, R., 2016. Extreme multimillennial slip rate variations on the Garlock fault, California: Strain super-cycles, potentially time-variable fault strength, and implications for system-level earthquake occurrence. Earth Planet. Sci. Lett. 446, 123-136. https://doi.org/10.1016/j.eps1.2016.04.011

Dor O, Ben-Zion Y, Rockwell TK, Brune J. Pulverized rocks in the Mojave section of the San Andreas Fault Zone. (2006) Earth and Planetary Science Letters. May 30;245(3-4):642-54. 
DuRoss, C. B., R. D. Gold, T. E. Dawson, K. M. Scharer, K. J. Kendrick, S. O. Akciz, S. J. Angster, J. Bachhuber, S. Bacon, S. EK. Bennett, et al. (2020). Surface Displacement Distributions for the July 2019 Ridgecrest, California, Earthquake Ruptures, Bull. Seismol. Soc. Am. XX, 1-19, doi: 10.1785/0120200058

Dunham, E.M., Belanger, D., Cong, L., Kozdon, J.E., 2011. Earthquake Ruptures with Strongly

Dziewonski, A. M., T.-A. Chou and J. H. Woodhouse, 1981, Determination of earthquake source

Ekström, G., M. Nettles, and A. M. Dziewonski, 2012, The global CMT project 2004-2010: Rate-Weakening Friction and Off-Fault Plasticity, Part 1: Planar FaultsEarthquake Ruptures with Strongly Rate-Weakening Friction and Off-Fault Plasticity, Part 1: Planar Faults. Bull. Seismol. Soc. Am. 101, 2296-2307. https://doi.org/10.1785/0120100075 parameters from waveform data for studies of global and regional seismicity, J. Geophys. Res., 86, 2825-2852, 1981. doi:10.1029/JB086iB04p02825 Centroid-moment tensors for 13,017 earthquakes, Phys. Earth Planet. Inter., 200-201, 19,. doi:10.1016/j.pepi.2012.04.002

Faulkner DR, Mitchell TM, Jensen E, Cembrano J. Scaling of fault damage zones with displacement and the implications for fault growth processes. Journal of Geophysical Research: Solid Earth. 2011 May;116(B5).

Fialko, Y., Sandwell, D., Simons, M., Rosen, P., 2005. Three-dimensional deformation caused by the Bam, Iran, earthquake and the origin of shallow slip deficit. Nature 435, 295. https://doi.org/10.1038/nature03425

Frankel, K.L., Glazner, A.F., Kirby, E., Monastero, F.C., Strane, M.D., Oskin, M.E., Unruh, J.R., Walker, J.D., Anandakrishnan, S., Bartley, J.M., Coleman, D.S., Dolan, J.F., Finkel, R.C., Greene, D., Kylander-Clark, A., Marrero, S., Owen, L.A., Phillips, F., 2008. Active tectonics of the eastern California shear zone, in: GSA Field Guide 11: Field Guide to Plutons, Volcanoes, Faults, Reefs, Dinosaurs, and Possible Glaciation in Selected Areas of Arizona, California, and Nevada. Geological Society of America, pp. 43-81. https://doi.org/10.1130/2008.fld011(03)

Freund, R., 1974. Kinematics of transform and transcurrent faults. Tectonophysics 21, 93-134. https://doi.org/10.1016/0040-1951(74)90064-X

Frost E, Dolan J, Sammis C, Hacker B, Cole J, Ratschbacher L. (2009) Progressive strain localization in a major strike-slip fault exhumed from midseismogenic depths: Structural 
observations from the Salzach-Ennstal-Mariazell-Puchberg fault system, Austria. Journal of Geophysical Research: Solid Earth. Apr;114(B4).

Gabriel, A.-A., Ampuero, J.-P., Dalguer, L.A., Mai, P.M., 2013. Source properties of dynamic rupture pulses with off-fault plasticity. J. Geophys. Res. Solid Earth 118, 4117-4126. https://doi.org/10.1002/jgrb.50213

Ganev, P.N., Dolan, J.F., McGill, S.F., Frankel, K.L., 2012. Constancy of geologic slip rate along the central Garlock fault: implications for strain accumulation and release in southern California. Geophys. J. Int. 190, 745-760. https://doi.org/10.1111/j.1365-

Gold, R.D., Reitman, N.G., Briggs, R.W., Barnhart, W.D., Hayes, G.P., Wilson, E., 2015. Onand off-fault deformation associated with the September 2013 Mw 7.7 Balochistan earthquake: Implications for geologic slip rate measurements. Tectonophysics 660, 6578. https://doi.org/10.1016/j.tecto.2015.08.019

Goldberg, D.E., Melgar, D., Sahakian, V.J., Thomas, A.M., Xu, X., Crowell, B.W., Geng, J., 2020. Complex Rupture of an Immature Fault Zone: A Simultaneous Kinematic Model of the 2019 Ridgecrest, CA Earthquakes. Geophys. Res. Lett. 47, e2019GL086382. https://doi.org/10.1029/2019GL086382

Hardebeck, J. L. (2020). A Stress-Similarity Triggering Model for Aftershocks of the Mw 6.4 and 7.1 Ridgecrest Earthquakes, Bull. Seismol. Soc. Am. 110, 1716-1727, doi: $10.1785 / 0120200015$

Hatem AE, Cooke ML, Toeneboehn K. Strain localization and evolving kinematic efficiency of initiating strike-slip faults within wet kaolin experiments. Journal of Structural Geology. 2017 Aug 1;101:96-108.

Hauksson E. State of stress from focal mechanisms before and after the 1992 Landers earthquake sequence. Bulletin of the Seismological Society of America. 1994 Jun 1;84(3):917-34.

Herbert, J.W., Cooke, M.L., Oskin, M., Difo, O., 2014. How much can off-fault deformation contribute to the slip rate discrepancy within the eastern California shear zone? Geology 42, 71-75. https://doi.org/10.1130/G34738.1

Hudnut, K.W., Seeber, L., Pacheco, J., 1989. Cross-fault triggering in the November 1987 Superstition Hills Earthquake Sequence, southern California. Geophys. Res. Lett. 16, 199-202. https://doi.org/10.1029/GL016i002p00199 
916 Jachens, R.C., Langenheim, V.E., Matti, J.C., 2002. Relationship of the 1999 Hector Mine and 1992 Landers Fault Ruptures to Offsets on Neogene Faults and Distribution of Late Cenozoic Basins in the Eastern California Shear Zone. Bull. Seismol. Soc. Am. 92, 1592-1605. https://doi.org/10.1785/0120000915

Ji, C., Wald, D.J., Helmberger, D.V., 2002. Source Description of the 1999 Hector Mine, California, Earthquake, Part I: Wavelet Domain Inversion Theory and Resolution Analysis. Bull. Seismol. Soc. Am. 92, 1192-1207. https://doi.org/10.1785/0120000916

Jin, Z., Fialko, Y.A., 2019. Rupture models of the 2019 M6.4-7.1 Ridgecrest earthquakes constrained by space geodetic data and aftershock locations. 1 Fall Meet. Abstr. 31.

Johnson, K.M., 2013. Slip rates and off-fault deformation in Southern California inferred from GPS data and models. Journal of Geophysical Research: Solid Earth, 118(10), pp.56435664.

Kilb, D. and Rubin, A.M., 2002. Relocated microearthquakes of the Mt. Lewis ML5. 7, California, earthquake sequence: Implications of diverse fault orientations. Journal of

934 Kim, Y.-S., D.C. Peacock, and D.J. Sanderson, 2004, Fault damage zones, J. Struct. Geol., 26, 935 503-517.

936 Kreemer, C., Blewitt, G., Klein, E.C., 2014. A geodetic plate motion and Global Strain Rate 937 Model. Geochem. Geophys. Geosystems 15, 3849-3889.

$938 \quad$ https://doi.org/10.1002/2014GC005407

939 Lavrentiadis G, Abrahamson N. Generation of Surface-Slip Profiles in the Wavenumber 940 Domain. Bulletin of the Seismological Society of America. 2019 Jun;109(3):888-907.

941 Li, Y. G., and J. E. Vidale (2001), Healing of the shallow fault zone from 1994-1998 after the 9421992 M7.5 Landers, California, earthquake, Geophys. Res. Lett., 28, 2999-3002, 943 doi:10.1029/2001GL012922.

944 Liu, C., Lay, T., Brodsky, E.E., Dascher-Cousineau, K., Xiong, X., 2019. Coseismic Rupture 945 Process of the Large 2019 Ridgecrest Earthquakes From Joint Inversion of Geodetic and 
Seismological Observations. Geophys. Res. Lett. 46, 11820-11829. https://doi.org/10.1029/2019GL084949

Marone, C.J., Scholtz, C.H., Bilham, R., 1991. On the mechanics of earthquake afterslip. J. Geophys. Res. Solid Earth 96, 8441-8452. https://doi.org/10.1029/91JB00275

McClusky, S.C., Bjornstad, S.C., Hager, B.H., King, R.W., Meade, B.J., Miller, M.M., Monastero, F.C., Souter, B.J., 2001. Present day kinematics of the Eastern California Shear Zone from a geodetically constrained block model. Geophys. Res. Lett. 28, 33693372. https://doi.org/10.1029/2001GL013091

Milliner, C.W.D., Dolan, J.F., Hollingsworth, J., Leprince, S., Ayoub, F., 2016. Comparison of coseismic near-field and off-fault surface deformation patterns of the $1992 \mathrm{Mw} 7.3$

McGuire, R.K., 1995. Probabilistic seismic hazard analysis and design earthquakes: Closing the loop. Bull. Seismol. Soc. Am. 85, 1275-1284.

McKenzie, D., Jackson, J., 1983. The relationship between strain rates, crustal thickening, palaeomagnetism, finite strain and fault movements within a deforming zone. Earth Planet. Sci. Lett. 65, 182-202. https://doi.org/10.1016/0012-821X(83)90198-X

Meade, B.J., Hager, B.H., 2005. Block models of crustal motion in southern California constrained by GPS measurements. J. Geophys. Res. Solid Earth 110. https://doi.org/10.1029/2004JB003209

Miller, D.M. and Yount, J.C., 2002. Late Cenozoic tectonic evolution of the north-central Mojave Desert inferred from fault history and physiographic evolution of the Fort Irwin area, California. Geologic evolution of the Mojave Desert and southwestern basin and range: Geological Society of America Memoir, 195, pp.173-198. Landers and $1999 \mathrm{Mw} 7.1$ Hector Mine earthquakes: Implications for controls on the distribution of surface strain. Geophys. Res. Lett. 43, 10,115-10,124. https://doi.org/10.1002/2016GL069841 
Mitchell, B.J., 1995. Anelastic structure and evolution of the continental crust and upper mantle from seismic surface wave attenuation. Rev. Geophys. 33, 441-462. https://doi.org/10.1029/95RG02074

Morelan, A.E. and Hernandez, J.L., 2020. Increasing Postearthquake Field Mapping Efficiency with Optical Image Correlation. Bulletin of the Seismological Society of America . 1-8, doi: $10.1785 / 0120200034$

Murthy, K., Shearn, M., Smiley, B.D., Chau, A.H., Levine, J. and Robinson, M.D., 2014, October. SkySat-1: very high-resolution imagery from a small satellite. In Sensors, Systems, and Next-Generation Satellites XVIII (Vol. 9241, p. 92411E). International Society for Optics and Photonics.

Oskin, M., Perg, L., Shelef, E., Strane, M., Gurney, E., Singer, B., Zhang, X., 2008. Elevated shear zone loading rate during an earthquake cluster in eastern California. Geology 36, 507-510. https://doi.org/10.1130/G24814A.1

Oskin, M. and Iriondo, A., 2004. Large-magnitude transient strain accumulation on the Blackwater fault, Eastern California shear zone. Geology, 32(4), pp.313-316. doi.org/10.1130/G20223.1

Ozacar, A.A., Beck, S.L., 2004. The 2002 Denali Fault and 2001 Kunlun Fault Earthquakes: Complex Rupture Processes of Two Large Strike-Slip Events. Bull. Seismol. Soc. Am. 94, S278-S292. https://doi.org/10.1785/0120040604

Petersen, M.D., Dawson, T.E., Chen, R., Cao, T., Wills, C.J., Schwartz, D.P., Frankel, A.D., 2011. Fault Displacement Hazard for Strike-Slip Faults Displacement Hazard for StrikeSlip Faults. Bull. Seismol. Soc. Am. 101, 805-825. https://doi.org/10.1785/0120100035

Peyrat, S., Olsen, K., Madariaga, R., 2001. Dynamic modeling of the 1992 Landers earthquake. J. Geophys. Res. Solid Earth 106, 26467-26482. https://doi.org/10.1029/2001JB000205

Platt J. Persistent slip rate discrepancies in the eastern California (USA) shear zone: Comment. Geology. 2017 Sep 1;45(9):e425-.

Platt, J.P., Becker, T.W., 2013. Kinematics of rotating panels of E-W faults in the San Andreas system: what can we tell from geodesy? Geophys. J. Int. 194, 1295-1301. https://doi.org/10.1093/gji/ggt189 
1004 Ponti, D.J., Blair, J.L., Rosa, C.M., K, T., Pickering, A.J., Morelan, A., Dawson, T., 2019.

1005 Digital datasets documenting surface fault rupture and ground deformation features produced by the Ridgecrest M6.4 and M7.1 earthquake sequence of July 4 and 5, 2019. US Geol. Surv. Data Release. https://doi.org/10.5066/P9BZ5IJ9

Ramsay, J.G., 1967. Folding And Fracturing Of Rocks. McGraw-Hill Book Company, New York p. 568.

Rice, J.R., 1975. On the stability of dilatant hardening for saturated rock masses. J. Geophys. Res. 1896-1977 80, 1531-1536. https://doi.org/10.1029/JB080i011p01531

Rockwell, T.K., Lindvall, S., Dawson, T., Langridge, R., Lettis, W., Klinger, Y., 2002. Lateral Offsets on Surveyed Cultural Features Resulting from the 1999 İzmit and Düzce Earthquakes, Turkey. Bull. Seismol. Soc. Am. 92, 79-94. https://doi.org/10.1785/0120000809

Rockwell, T.K., Lindvall, S., Herzberg, M., Murbach, D., Dawson, T., Berger, G., 2000. Paleoseismology of the Johnson Valley, Kickapoo, and Homestead Valley Faults: Clustering of Earthquakes in the Eastern California Shear Zone. Bull. Seismol. Soc. Am. 90, 1200-1236. https://doi.org/10.1785/0119990023

Ron, H., Freund, R., Garfunkel, Z., Nur, A., 1984. Block rotation by strike-slip faulting: Structural and paleomagnetic evidence. J. Geophys. Res. Solid Earth 89, 6256-6270. https://doi.org/10.1029/JB089iB07p06256

Rousseau, C.E. and Rosakis, A.J., 2003. On the influence of fault bends on the growth of subRayleigh and intersonic dynamic shear ruptures. Journal of Geophysical Research: Solid Earth, 108(B9).

Ross, Z.E., Idini, B., Jia, Z., Stephenson, O.L., Zhong, M., Wang, X., Zhan, Z., Simons, M., Fielding, E.J., Yun, S.-H., Hauksson, E., Moore, A.W., Liu, Z., Jung, J., 2019. Hierarchical interlocked orthogonal faulting in the 2019 Ridgecrest earthquake sequence. Science 366, 346-351. https://doi.org/10.1126/science.aaz0109

Sammis, C.G., Rosakis, A.J., Bhat, H.S., 2010. Effects of Off-fault Damage on Earthquake Rupture Propagation: Experimental Studies, in: Ben-Zion, Y., Sammis, C. (Eds.), Mechanics, Structure and Evolution of Fault Zones, Pageoph Topical Volumes. Birkhäuser, Basel, pp. 1629-1648. https://doi.org/10.1007/978-3-0346-0138-2_5 
1034 Savage, J.C., Burford, R.O., 1973. Geodetic determination of relative plate motion in central California. J. Geophys. Res. 1896-1977 78, 832-845. https://doi.org/10.1029/JB078i005p00832

Savage, J.C., Gan, W., Svarc, J.L., 2001. Strain accumulation and rotation in the Eastern California Shear Zone. J. Geophys. Res. Solid Earth 106, 21995-22007. https://doi.org/10.1029/2000JB000127

Savage, J.C., Svarc, J.L. and Prescott, W.H., 2004. Interseismic strain and rotation rates in the northeast Mojave domain, eastern California. Journal of Geophysical Research: Solid Earth, 109(B2). https://doi.org/10.1029/2003JB002705

Scharer, K.M., Salisbury, J.B., Arrowsmith, J.R., Rockwell, T.K., 2014. Southern San Andreas Fault Evaluation Field Activity: Approaches to Measuring Small Geomorphic OffsetsChallenges and Recommendations for Active Fault Studies. Seismol. Res. Lett. 85, 6876. https://doi.org/10.1785/0220130108

Schermer, E.R., Luyendyk, B.P. and Cisowski, S., 1996. Late Cenozoic structure and tectonics of the northern Mojave Desert. Tectonics, 15(5), pp.905-932.

Scholz, C.H., 2019. The mechanics of earthquakes and faulting. Cambridge university press.

Scott, C.P., Arrowsmith, J.R., Nissen, E., Lajoie, L., Maruyama, T., Chiba, T., 2018. The M7 2016 Kumamoto, Japan, Earthquake: 3-D Deformation Along the Fault and Within the Damage Zone Constrained From Differential Lidar Topography. J. Geophys. Res. Solid Earth 123, 6138-6155. https://doi.org/10.1029/2018JB015581

Shelef, E., Oskin, M., 2010. Deformation processes adjacent to active faults: Examples from eastern California. J. Geophys. Res. Solid Earth 115. https://doi.org/10.1029/2009JB006289

Shi Z, Day SM., 2013, Rupture dynamics and ground motion from 3-D rough-fault simulations. Journal of Geophysical Research: Solid Earth. Mar;118(3):1122-41.

Sieh, K., Jones, L., Hauksson, E., Hudnut, K., Eberhart-Phillips, D., Heaton, T., Hough, S., Hutton, K., Kanamori, H., Lilje, A. and Lindvall, S., 1993. Near-field investigations of the Landers earthquake sequence, April to July 1992. Science, 260(5105), pp.171-176.

Smith, K., Hatch, R. L., Ruhl, C. J., \& Abercrombie, R. E. (2020, 08). Order and timing of highangle conjugate strike-slip faulting in Walker Lane sequences. Poster Presentation at 2020 SCEC Annual Meeting. 
1065 Socquet, A., Hollingsworth, J., Pathier, E., Bouchon, M., 2019. Evidence of supershear during 1066 the 2018 magnitude 7.5 Palu earthquake from space geodesy. Nat. Geosci. 12, 192-199. https://doi.org/10.1038/s41561-018-0296-0

1068 Stirling MW, Wesnousky SG, Shimazaki K. Fault trace complexity, cumulative slip, and the 1069 1070 shape of the magnitude-frequency distribution for strike-slip faults: A global survey.

Teran, O.J., Fletcher, J.M., Oskin, M.E., Rockwell, T.K., Hudnut, K.W., Spelz, R.M., Akciz, 1074 1075 Geophysical Journal International. 1996 Mar 1;124(3):833-68.

Tchalenko JS. Similarities between shear zones of different magnitudes. Geological Society of America Bulletin. 1970 Jun 1;81(6):1625-40.

U.S. Geological Survey and California Geological Survey, Quaternary fault and fold database for the United States, accessed March 1 2020, at: https://www.usgs.gov/naturalhazards/earthquake-hazards/faults. S.O., Hernandez-Flores, A.P., Morelan, A.E., 2015. Geologic and structural controls on rupture zone fabric: A field-based study of the $2010 \mathrm{Mw} 7.2 \mathrm{El}$ Mayor-Cucapah earthquake surface rupture. Geosphere 11, 899-920. https://doi.org/10.1130/GES01078.1

Thomas, M.Y., Bhat, H.S., 2018. Dynamic evolution of off-fault medium during an earthquake: a micromechanics based model. Geophys. J. Int. 214, 1267-1280. https://doi.org/10.1093/gji/ggy129

Vidale JE, Li YG. Damage to the shallow Landers fault from the nearby Hector Mine earthquake. 2003, Nature Jan;421(6922):524-6.

Wang, K., Dreger, D. S., Tinti, E., Bürgmann, R., and Taira, T., 2020, Rupture process of the 2019 Ridgecrest, California M6.4 Foreshock and M7.1 Earthquake Constrained by Seismic and Geodetic Data, Bull. Seismol. Soc. Am. 92, https://doi.org/10.1785/0120200108

Wesnousky, S.G., 1988. Seismological and structural evolution of strike-slip faults. Nature, 335(6188), pp.340-343.

Wesnousky, S.G., 2005. The San Andreas and Walker Lane fault systems, western North 1094 America: transpression, transtension, cumulative slip and the structural evolution of a major transform plate boundary. J. Struct. Geol. 27, 1505-1512. https://doi.org/10.1016/j.jsg.2005.01.015 
1095 Willis, MJ; Barnhart, WD; Cassotto, R; Klassen, J; Corcoran, J; Host, T; Huberty, B., Pelletier, K., Knight, J.F., CaliDEM: Ridgecrest, CA Region $2 m$ Digital Surface Elevation Model. Funding by NSF and USGS. Data collection by DigitalGlobe. Distributed by OpenTopography. https://doi.org/10.5069/G998854C

$\mathrm{Xu}, \mathrm{S}$., and Y. Ben-Zion, 2013, Numerical and theoretical analyses of in-plane dynamic rupture

Xu, X., Sandwell, D.T., Smith-Konter, B., 2020. Coseismic Displacements and Surface Fractures from Sentinel-1 InSAR: 2019 Ridgecrest Earthquakes. Seismol. Res. Lett. https://doi.org/10.1785/0220190275 on a frictional interface and off-fault yielding patterns at different scales: Geophys. J. Int., 193, 304-320.

Zinke, R., Hollingsworth, J. and Dolan, J.F., 2014. Surface slip and off-fault deformation patterns in the 2013 MW 7.7 B alochistan, Pakistan earthquake: Implications for controls on the distribution of near-surface coseismic slip. Geochemistry, Geophysics,

1112 Zhou, Y., Parsons, B.E., Walker, R.T., 2018. Characterizing Complex Surface Ruptures in the 2013 Mw 7.7 Balochistan Earthquake Using Three-Dimensional Displacements. J. Geophys. Res. Solid Earth 123, 10,191-10,211. https://doi.org/10.1029/2018JB016043

1122 Table 1 Summary of statistics and values estimated for the foreshock fault rupture that includes 1123 comparisons of observed and predicted values for the bookshelf slip model. 


\begin{tabular}{|c|c|c|}
\hline Angle between faults $\left(\alpha, \frac{0}{)}\right)$ & 86 & - \\
\hline Sinistral slip $\left(\gamma^{\prime}\right.$, meter $)$ & $0.71-1.4$ & 0.97 \\
\hline Cumulative displacement ( $d_{f \circ r e}$ ) & $256-600$ & - \\
\hline Total long-term block rotation $\left(\omega_{T}, \frac{0}{)}\right)$ & 3-7 & - \\
\hline Mean displacement ( $d$, meter) & 0.71 & - \\
\hline Maximum displacement, (meter) & 1.4 & - \\
\hline $\begin{array}{l}\text { Median off-fault deformation (OFD, } \\
\%)\end{array}$ & 65 & - \\
\hline Mean off-fault deformation (OFD, \%) & 56 & - \\
\hline Mean Fault zone width & 59 & - \\
\hline Shallow slip deficit (\%) & $42-65^{*}$ & - \\
\hline
\end{tabular}

*(Chen et al., 2020; Jin \& Fialko, 2020; Wang et al., 2020; Xu et al., 2020)

Table 2 Summary of statistics and values estimated for the mainshock fault rupture that includes comparison of observed and predicted values for the bookshelf slip model.

\begin{tabular}{|c|c|c|}
\hline & Observed & Predicted \\
\hline Dextral slip $(\gamma$, meter $)$ & 1.6 & - \\
\hline Angle between faults $(\alpha, \stackrel{o}{)}$ & 66 & - \\
\hline Sinistral slip ( $\gamma^{\prime}$, meter $)$ & 0.8 & 1 \\
\hline Instantaneous block rotation $(\omega, \stackrel{0}{)}$ & 0.06 & 0.05 \\
\hline Internal block strain $(e, \%)$ & 0.004 & 0.0044 \\
\hline Mean displacement ( $d$, meter) & 1.69 & - \\
\hline Macroscopic block width ( $w_{b}$, meter) & 4,890 & \\
\hline $\begin{array}{l}\text { Median off-fault deformation (OFD, } \\
\% \text { ) }\end{array}$ & 25 & - \\
\hline Mean off-fault deformation (OFD, \%) & 34 & - \\
\hline $\begin{array}{l}\text { Mean Fault zone width ( fault zone } \\
\text { width, meter) }\end{array}$ & 69 & - \\
\hline Shallow slip deficit (\%) & $18-35^{*}$ & - \\
\hline
\end{tabular}

*(Chen et al., 2020; Jin \& Fialko, 2020; Wang et al., 2020; Xu et al., 2020) 


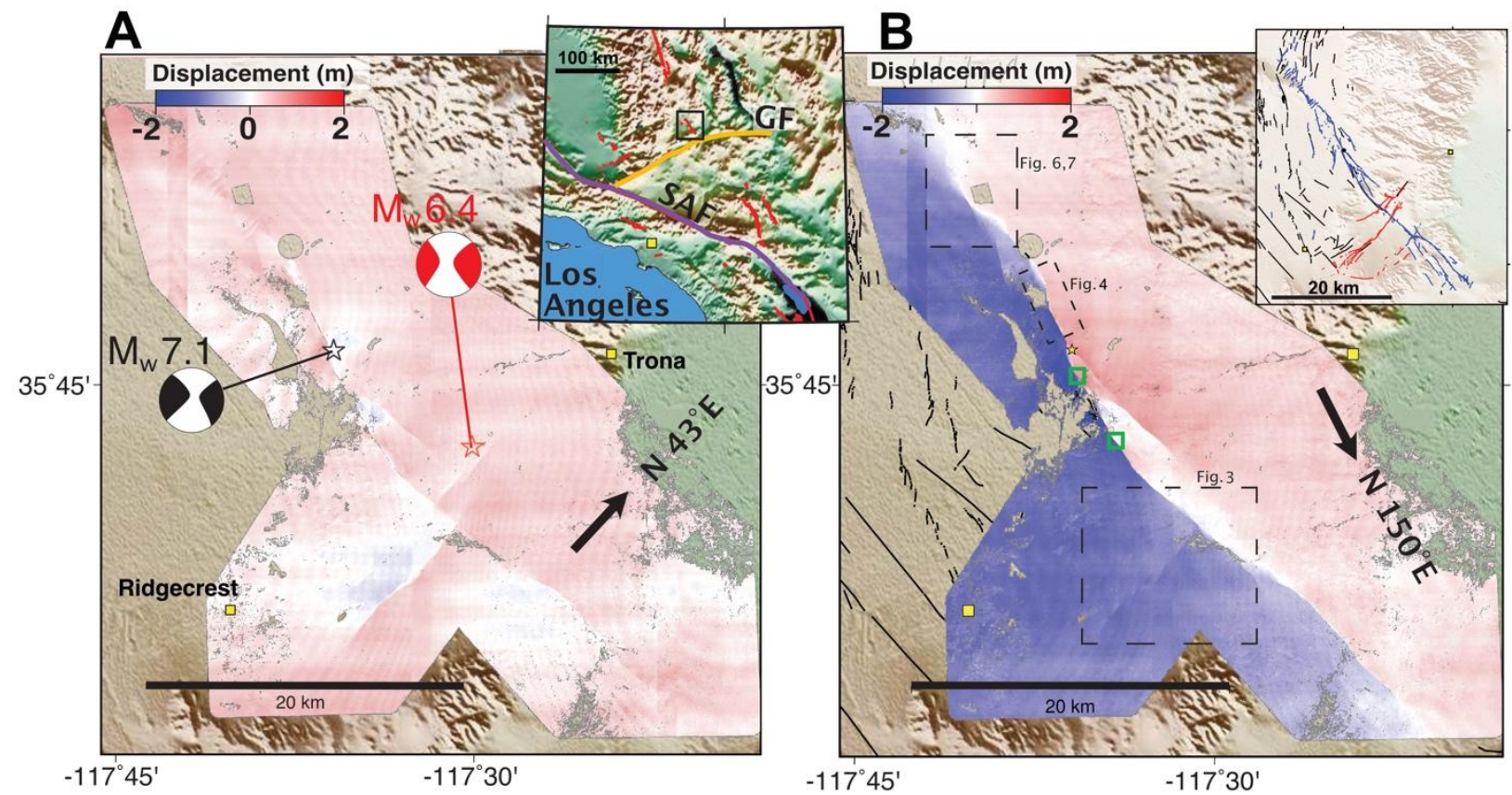

1139 Figure 1. Displacement maps from optical image correlation that measures surface motion

1140 from both the foreshock (July $\left.4^{\text {th }}, 2019\right)$ and mainshock ruptures (July $\left.6^{\text {th }}, 2019\right)$. The pre-

1141 event image was acquired on September 15th, 2018 and the post image on July 24th, 2019 and

1142 therefore surface motion from both events are found within the surface displacement maps. A)

1143 Displacement projected into the $\mathrm{N} 43^{\circ} \mathrm{E}$ direction parallel to foreshock faults. Inset shows the

1144 location of Ridgecrest region (black rectangle), San Andreas fault (SAF, purple line) and Garlock

1145 fault (GF, orange line). B) Displacement projected into the $\mathrm{N} 150^{\circ} \mathrm{E}$ direction, parallel to mainshock

1146 faults. Focal mechanisms from CMT catalogue. (Dziewonski et al., 1981; Ekström et al., 2012).

1147 Inset in upper right shows fault rupture traces of the foreshock (red) and mainshock (blue) mapped

1148 from field surveys (Ponti et al., 2019), with black lines showing Quaternary mapped faults (USGS, 1149 2020). Green boxes along central segment of rupture show the location of transpressional bends. 


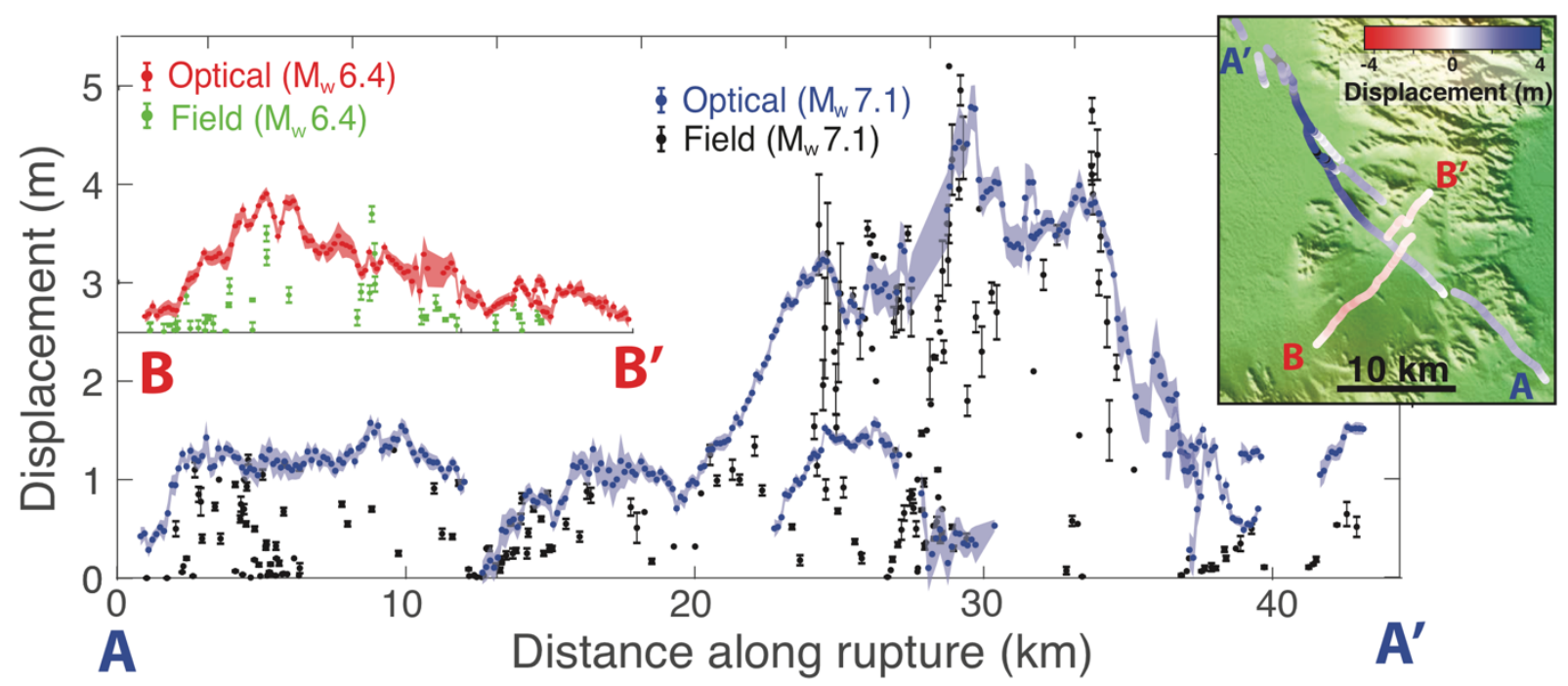

Figure 2. Comparison of slip profiles of the foreshock and mainshock events made from field

1154 and optical measurements. Slip along the foreshock is measured along three parallel fault strands

1155 and slip along the mainshock is measured along eight. Red and green values show optical and field

1156 measurements along the foreshock rupture, respectively, and blue and black are optical and field 1157 measurements along the mainshock, respectively. Optical displacements capture the total 1158 displacement across the surface rupture using profiles with $>0.5 \mathrm{~km}$ in across-fault length (e.g., 1159 Figure S1), which includes both on-fault displacement and off-fault distributed inelastic strain, 1160 explaining why the majority are larger than the field displacement measurements from Ponti et al. 1161 (2019). Inset in top right shows the same optical displacement measurements in map view. 

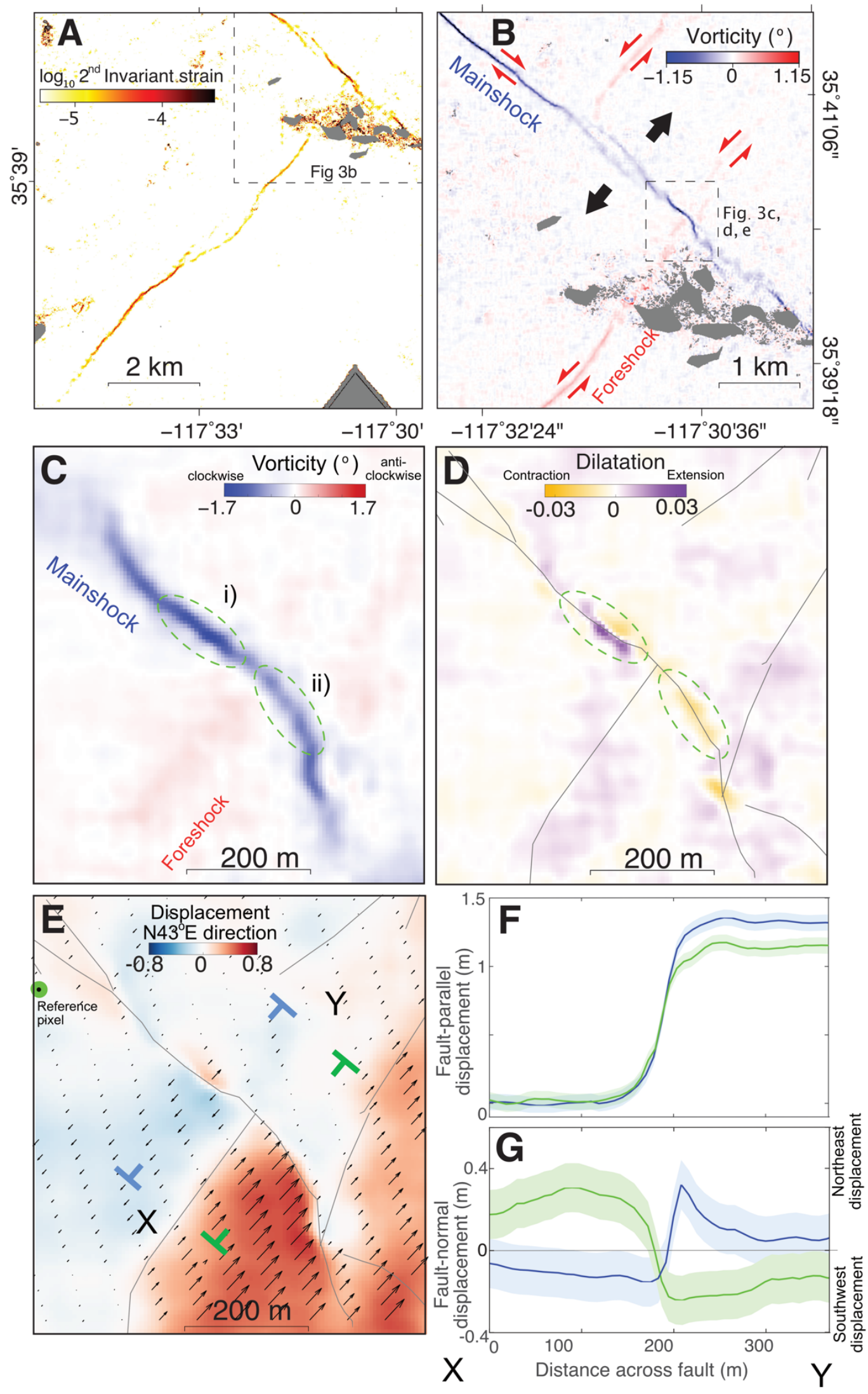
1165 Figure 3. Strain maps of the foreshock-mainshock intersection region illustrating how strain 1166 release along the mainshock was affected by the foreshock rupture. a) Logarithm of $I_{2}$, which

1167 illustrates how the scalar strain intensity varies along the rupture. b) Vorticity map illustrating the 1168 different shear senses around the mainshock-foreshock intersection. c) Zoom of vorticity map 1169 illustrating an increase along segment i) and lower values along segment ii), suggesting a possible 1170 difference in the intensity of simple shear strain. d) Dilatation of the intersection region 1171 highlighting how different segments experienced contraction (orange) and extension (purple) due 1172 to imposed stress changes from the foreshock rupture. Gray lines show major fault traces from 1173 field mapping (Ponti et al., 2019). e) Surface displacement projected into the NE direction, 1174 illustrating motion perpendicular to the mainshock rupture shown both by the colors (amplitude of 1175 motion) and the vectors. This shows clear extension across the blue profile (vectors diverging away 1176 from each across the mainshock rupture) and contraction across the green profile (shown by 1177 vectors converging across the mainshock rupture, profiles labelled $X-Y$ ). f) and g) show surface 1178 motion that is projected in the direction parallel to and perpendicular to the strike of the mainshock 1179 rupture, respectively, along profiles located between $\mathrm{X}$ and $\mathrm{Y}$. 


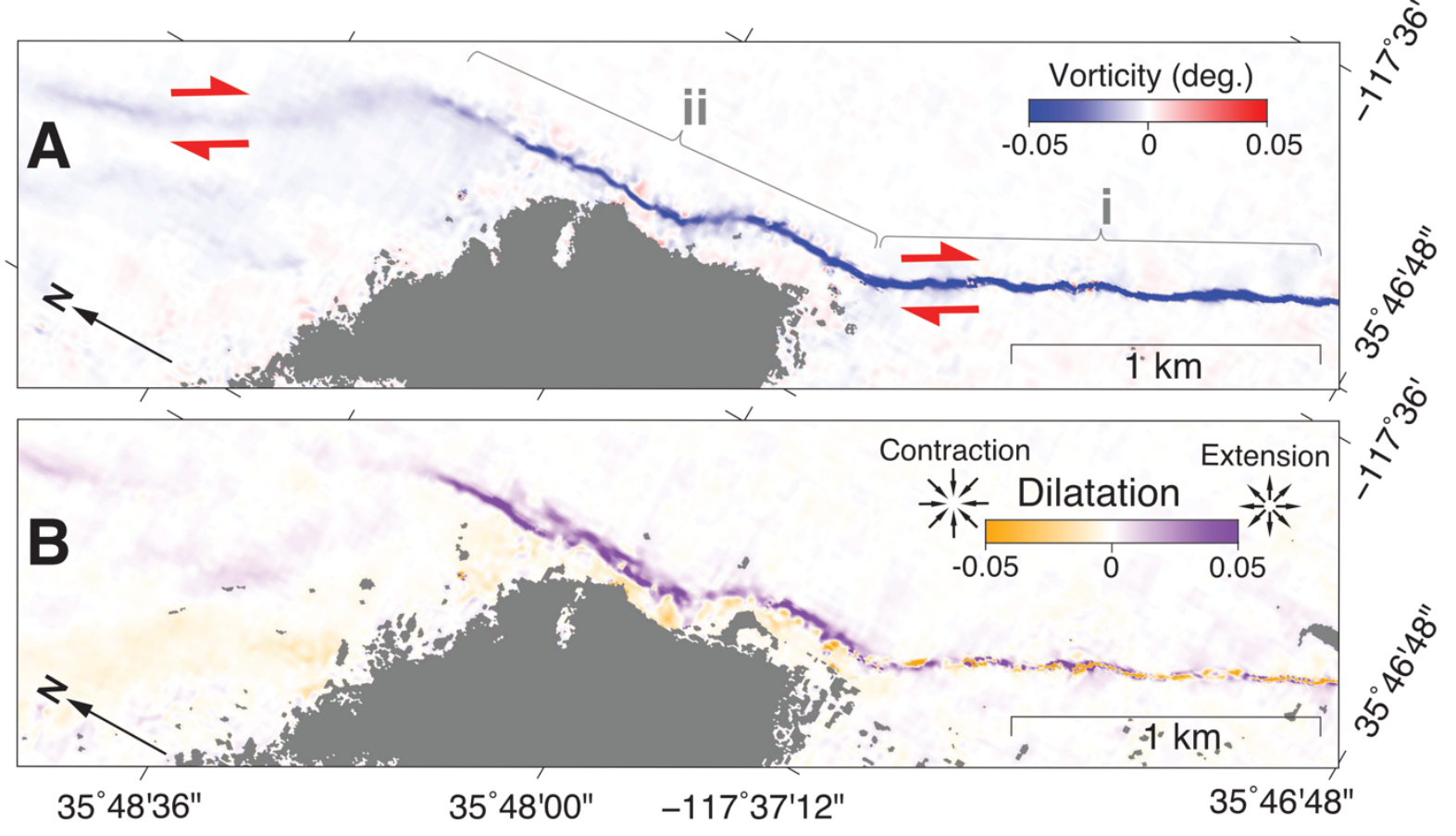

Figure 4. Strain maps along a transtensional bend. A) Vorticity along a transtensional bend

1184 located near the northern end of the mainshock rupture (see Figure 1 for location), segments $i$ and

1185 ii show location of profiles used in Fig. 4b and c. B) Dilatational strain component along the

1186 transtensional bend showing systematic variations of width between the bend and adjacent linear 1187 segment, and variations of the type of dilatation according to subtle curvature of the fault along 1188 segment i. See Figure 1 for locations. Gray area is region of decorrelation due to changing playa 1189 surface. 
A 1202 in ii.
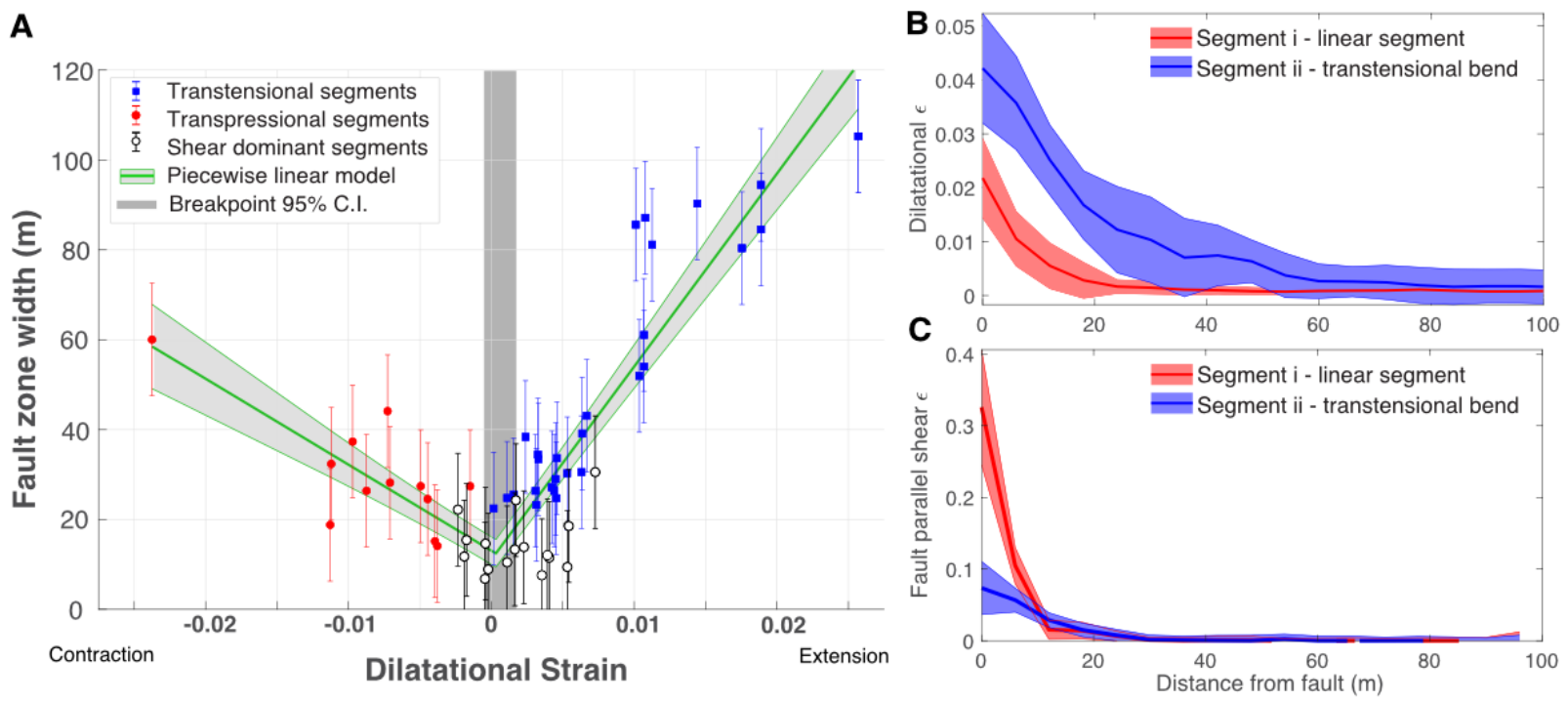

Figure 5. Variation of fault zone width with dilatational strain. A) Fault width measured from three different strain regimes, contractional (red), shear dominated (white), and extensional (blue), which shows that a segmented piecewise linear function can explain the variation, with wider fault zones with increasing amounts of dilatational strain. Dark vertical gray band is $95 \%$ confidence interval of the breakpoint estimated by bootstrapping the data with 3000 simulations. Light gray bands are 95\% confidence intervals of the segmented regression. B) shows the decay of inelastic strain from strain profiles taken across the transtensional bend (segment ii) from the dilatation map shown in Fig. 4b, where dilatational strain is significantly wider along the transtensional bend than the adjacent segment (segment i) that experiences mostly shear strain. C) shows fault-parallel shear strain, with high-strain fault core along segment $i$ and lower shear strains 

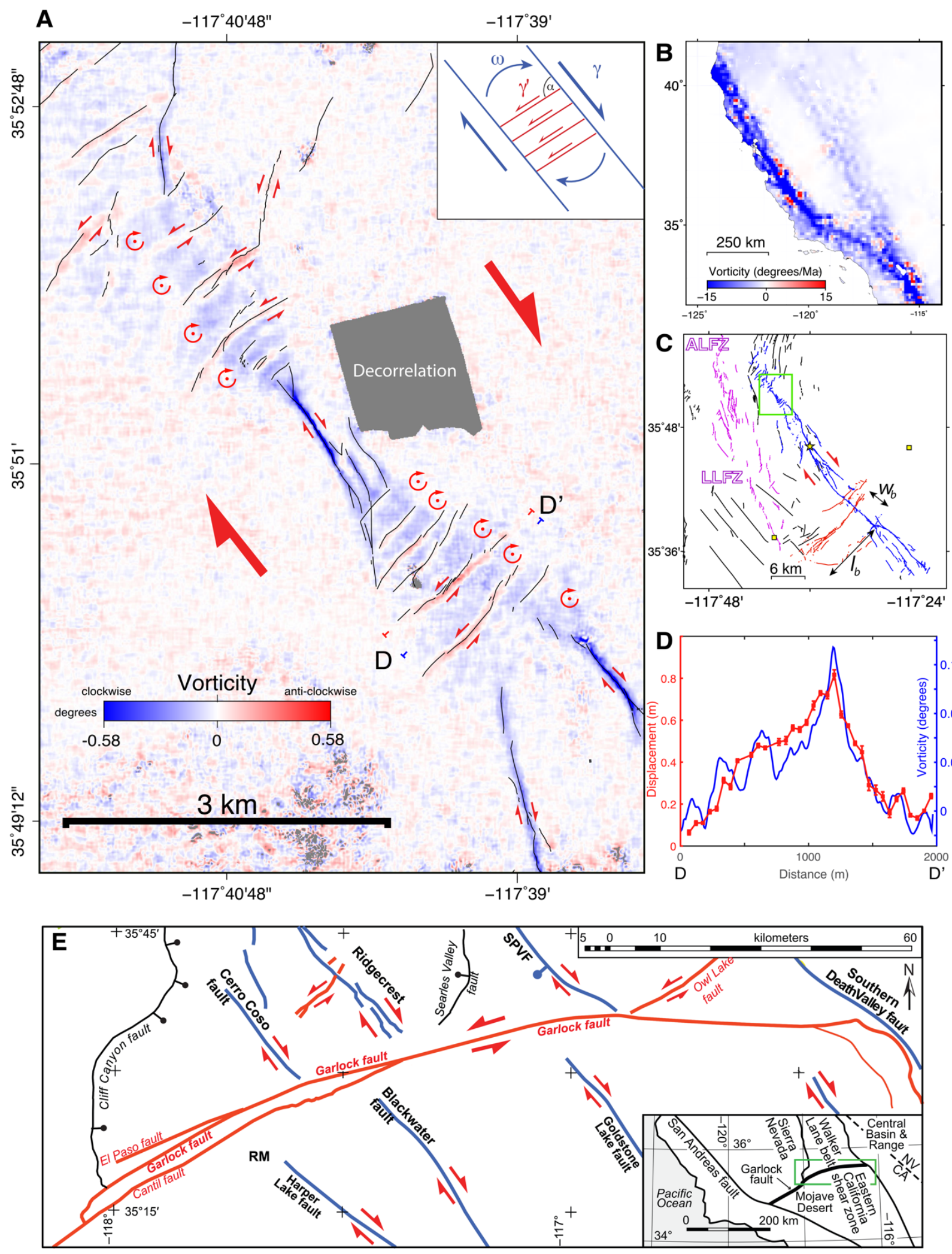
1204 Figure 6. Vorticity of the vector field illustrating bookshelf faulting and rotations associated

1205 with simple shear. Location is shown as the green box in c) and Figure 1. A) Positive (negative)

1206 colors show anti-clockwise (clockwise) rotation in a right-handed coordinate system. Black lines

1207 are faults mapped in the field (Ponti et al., 2019). The vorticity illustrates that strain beyond the

1208 fault tips of dextral faults transition to rotation, where according to field mapping (black lines)

1209 fracturing is only limited to larger, finite amounts of strain, suggesting rotation accommodates

1210 lower strains between faults. Inset shows schematic illustrating the kinematics of bookshelf slip

1211 model consisting of regional dextral displacement (blue lines, $\gamma)$, rotation of blocks $(\omega)$, rotation

1212 of sinistral oblique fault $(\alpha)$, and slip on oblique faults (red, $\gamma^{\prime}$ ), modified from Platt \& Becker

1213 (2013). B) Vorticity rate from GPS velocities along the North America-Pacific plate boundary,

1214 blue is clockwise, red anticlockwise from Kremeer et al. (2014). C) Fault traces of the foreshock

1215 rupture (red), mainshock (blue) and Little Lake and Airport Fault Zones (LLFZ, ALFZ, magenta),

1216 illustrating the larger scale 'bookshelf' with block width $\left(w_{b}\right)$. D) Profile of vorticity and

1217 displacement along and adjacent to the second southernmost sinistral fault (note displacement is

1218 measured from displacement map shown in Fig. 6b), where a non-constant vorticity and slip is

1219 evidence of non-rigid block strain. E) Map view of NW-trending dextral faults of the ECSZ show

1220 that they do not intersect with the sinistral WSW-trending Garlock fault, which could be explained

1221 by clockwise block rotation beyond the tips of dextral faults similar to that found in a), figure

1222 adapted from Andrew et al. (2015).

1223 

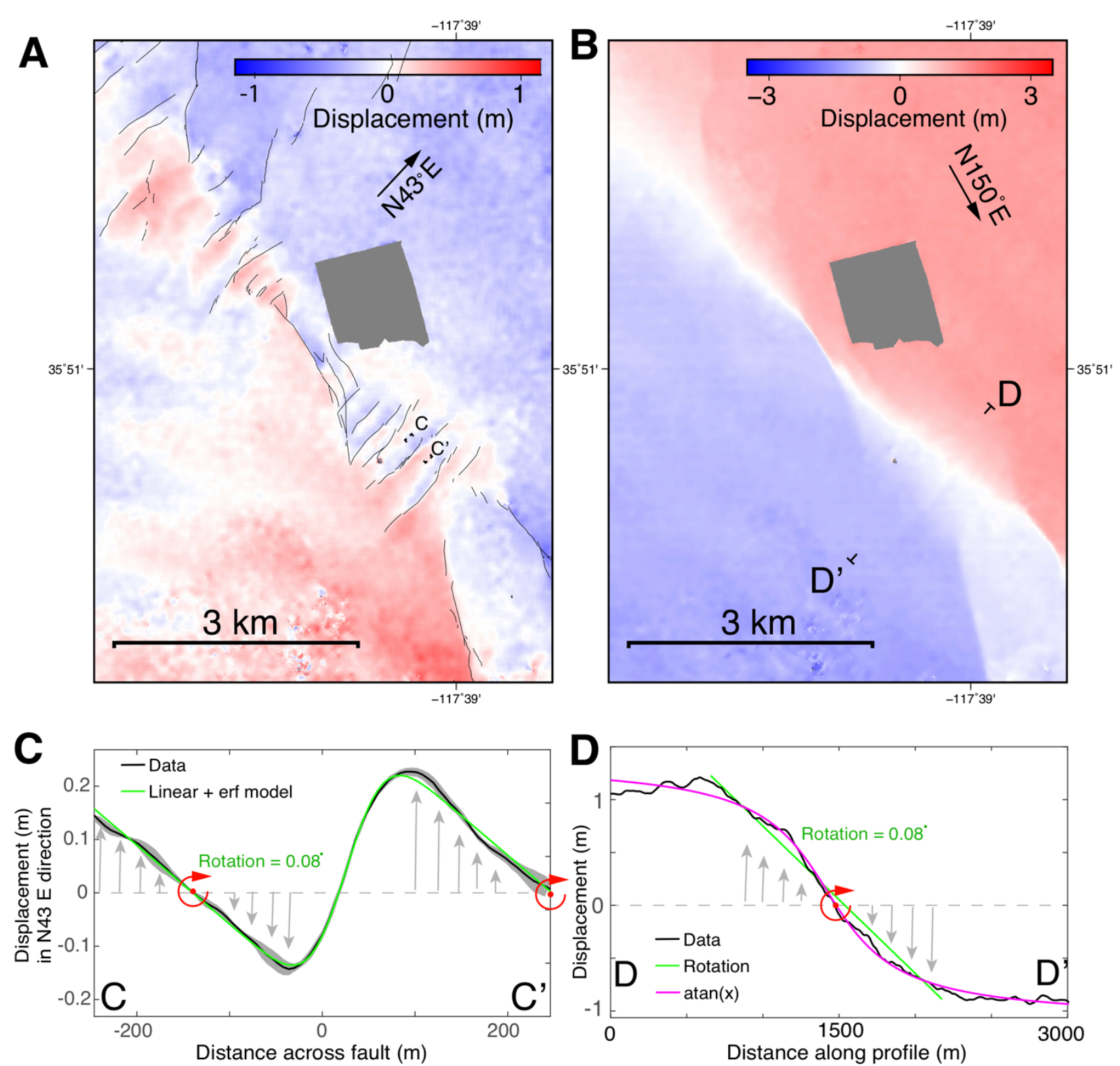

Figure 7. Projected surface displacement illustrating bookshelf kinematics. Location shown

1226 in Figure 1. A) shows displacement projected into NE that highlights motion along the oblique NE

1227 trending sinistral faults and contraction of dextral faults, while b) shows displacement projected 1228 into SE direction parallel to the NW-trending dextral faults illustrating distributed shear across the 1229 bookshelf. C) shows profile of displacement from a) normal to one of the sinistral oblique faults 1230 illustrating rotation of displacement discontinuities (location is shown in panel A between the 1231 labels C-C'). D) shows that distributed shear across the bookshelf is not well explained by constant 1232 motion (green line) indicative of rigid-block rotation, but instead by shear that increases towards 1233 the center of the 'bookshelf' described by an arctan function from a screw dislocation model 1234 (location of profile is shown in b), between labels D and D'). Inverting the surface motion (black 
1235 line) suggests a possible single, freely slipping, discrete fault that reaches from depth to $342 \mathrm{~m}$ 1236 below the surface (magenta line). 


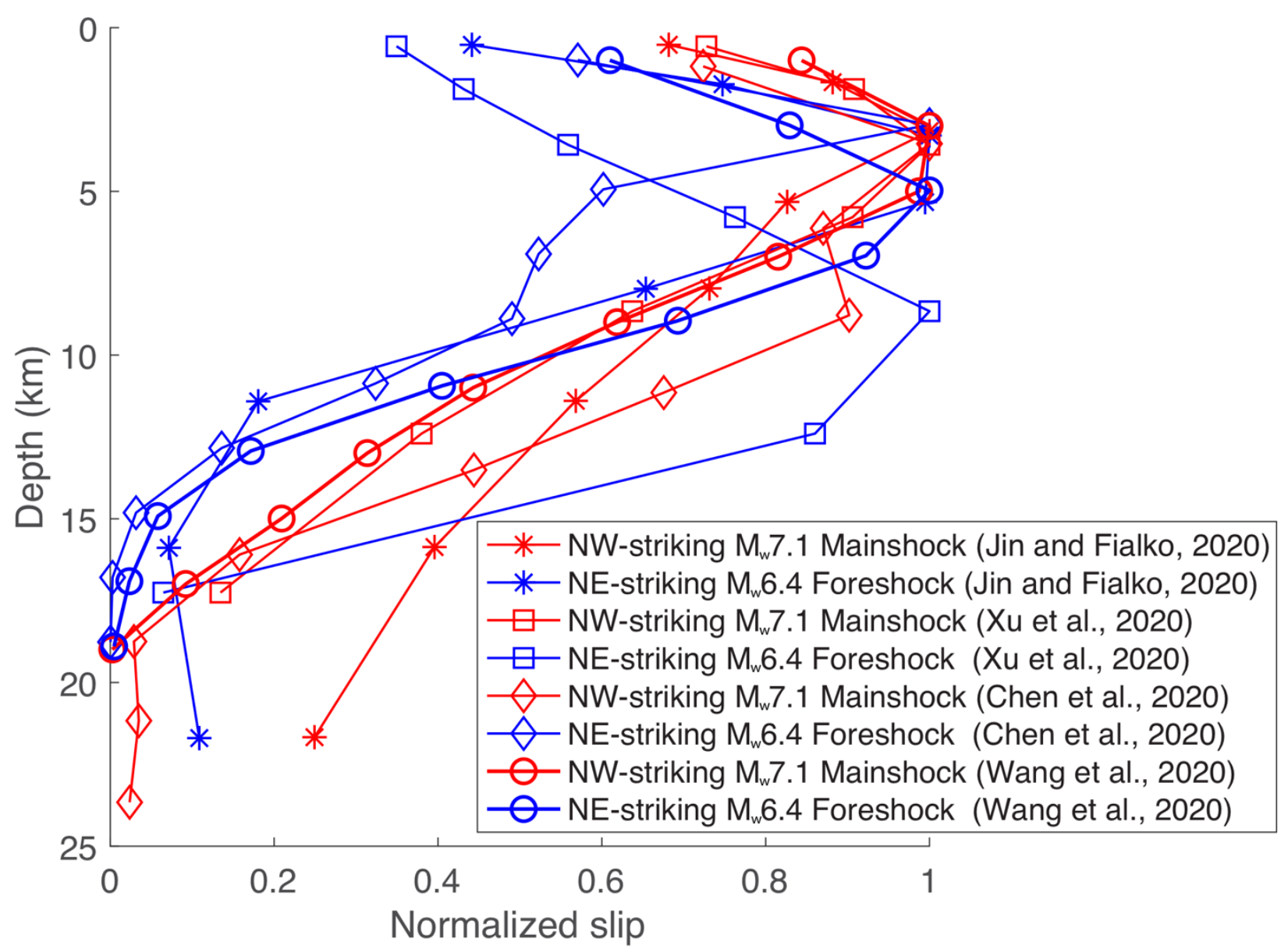

Figure 8. Normalized slip depth distributions for the $M_{w} 6.4$ foreshock (blue) and the $M_{w} 7.1$ mainshock (red) from different slip inversions. Here we have assumed that the $M_{w} 6.4$ foreshock

1241 rupture was mainly along the NE-striking sinistral fault segments, whereas the $\mathrm{M}_{\mathrm{w}} 7.1$ mainshock 1242 rupture was along the NW-striking dextral faults, although seismicity and inversion of seismic and 1243 geodetic data suggest that the $\mathrm{M}_{\mathrm{w}} 6.4$ foreshock may involve rupturing along the NW-striking 1244 faults too (Ross et al., 2019; Chen et al., 2020; Wang et al., 2020). Despite large variations among 1245 these models they all systematically show that the foreshock had a higher shallow slip deficit 1246 ranging from $42-65 \%$ while the mainshock ranges from 18-35\% (Chen et al., 2020; Jin and Fialko, 1247 2020; Wang et al., 2020; Xu et al., 2020). 